\title{
Effect of building overtopping on induced loads during extreme hydrodynamic events
}

Davide Wüthrich(Post-Doctoral researcher), Michael Pfister (Professor), loan Nistor(Professor) \& Anton J. Schleiss(Professor)

To cite this article: Davide Wüthrich(Post-Doctoral researcher), Michael Pfister (Professor), loan Nistor(Professor) \& Anton J. Schleiss(Professor) (2020) Effect of building overtopping on induced loads during extreme hydrodynamic events, Journal of Hydraulic Research, 58:2, 289-304, DOI: 10.1080/00221686.2019.1573764

To link to this article: https://doi.org/10.1080/00221686.2019.1573764

曲 Published online: 29 Mar 2019.

Submit your article to this journal ¿

Џll Article views: 256

Q View related articles $\square$

View Crossmark data ¿

Citing articles: 2 View citing articles 5 
Research paper

\title{
Effect of building overtopping on induced loads during extreme hydrodynamic events
}

DAVIDE WÜTHRICH (D), Post-Doctoral researcher, Laboratory of Hydraulic Constructions (LCH), Ecole Polytechnique Fédérale de Lausanne (EPFL), ENAC, Station 18, Lausanne 1015, Switzerland

Email:d.wuthrich@uq.edu.au (authorfor correspondence)

MICHAEL PFISTER, Professor, Civil Engineering Department, Haute Ecole d'Ingénierie et d'Architecture de Fribourg (HEIA-FR, HES-SO), Fribourg, Switzerland

Email: michael.pfister@hefr.ch

IOAN NISTOR (D), Professor, Department of Civil Engineering, University of Ottawa, 161 Louis-Pasteur, Ottawa, ON K1N 6N5, Canada

Email: inistor@uottawa.ca

ANTON J. SCHLEISS (D), Professor, Laboratory of Hydraulic Constructions (LCH), Ecole Polytechnique Fédérale de Lausanne (EPFL), ENAC, Station 18, Lausanne 1015, Switzerland

Email: anton.schleiss@epfl.ch

\begin{abstract}
Tsunamis, impulse-waves and dam-break waves have affected humanity in recent decades and the construction of vertical shelters can provide safety to people. However, for non-critical infrastructures, typically residential houses of lower height, overtopping is accepted during such events. This study experimentally quantifies the effect of building overtopping, i.e. water flowing over the roof, on the resulting loading process. Both surges and bores were investigated and the impact against buildings with two different heights was assessed. Detailed measurements of forces and moments allowed key differences to be captured between the scenarios with and without overtopping. Results showed that overtopping induced higher downstream water depths, leading to lower horizontal forces and a reduced resistance coefficient. Furthermore, cantilever arm, moment and impulse values were constantly lower in case of overtopping. Finally, this study presents an innovative methodology to assess the main loading features of buildings subject to overtopping, supporting engineers to design safer resilient structures.
\end{abstract}

Keywords: Hydrodynamic loading; overtopping; tsunami; unsteady flows; wave impact

\section{Introduction}

Over the past decades the world has seen some catastrophic events such as the 2004 Indian Ocean Tsunami and the 2011 Tohoku Tsunami in Japan. These events led to the destruction of multiple buildings, increasing interest in an improved design of free-standing buildings conceived as vertical shelters. These should be designed to withstand impact forces induced by tsunami inundations, thereby guaranteeing safety to people. Obviously, these buildings should not be overtopped. However, some of the non-critical infrastructures are not designed to serve as vertical shelters, and overtopping of the building can occur.
Most previous studies focused on free-standing buildings designated as vertical shelters. Among others, Cross (1967), Ramsden (1996), Asakura et al. (2000), Arnason, Petroff, and Yeh (2009), Lukkunaprasit, Thanasisathit, and Yeh (2009), Fujima, Achmad, Shigihara, and Mizutani (2009), Nouri, Nistor, Palermo, and Cornett (2010), Al-Faesly, Palermo, Nistor, and Cornett (2012), Foster, Rossetto, and Allsop (2017) and Wüthrich, Pfister, Nistor, and Schleiss (2018b) have all conducted research on hydrodynamic loading on structures or structural elements. Qi, Eames, and Johnson (2014) investigated the fluid-structure interaction under steady flow conditions while the effect of building orientation was investigated by Shafiei, Melville, and Shamseldin (2016). The effect of building open-

Received 1 May 2018; accepted 21 January 2019/Open for discussion until 1 November 2020. 
ings was addressed by Wüthrich, Pfister, Nistor, and Schleiss (2018c).

To the authors' knowledge, limited literature is available for low-rise coastal buildings overtopped by incoming surges and bores (Asakura et al., 2000; Iizuka \& Matsutomi, 2000; Rahman, Akib, Khan, \& Shirazi, 2014), representing the majority of the buildings standing along the coastline. Forces induced by waves overtopping a coastal dike and impacting against a vertical wall were experimentally investigated by Chen, Hofland, Altomare, Suzuki, and Uijttewaal (2015) and Chen, Hofland, and Uijttewaal (2016). These studies provided an empirical formula to compute the impact loads on a sea wall as a function of the hydrodynamic properties of the incoming waves and the dike geometry. Most recently, Esteban et al. (2017) investigated the effect of tsunami overtopping of concrete coastal dikes, focusing on inundation depths behind the structures. The same study also provided preliminary tools to predict whether a structure would be overtopped based on the structural and wave hydrodynamic properties. Several previous studies (Nouri et al., 2010; Ramsden, 1996; Wüthrich, Pfister, Nistor, \& Schleiss, 2018a) showed that both surges propagating on a dry bed (representing the first incoming wave) and bores propagating over an initially still water layer (representing any subsequent wave), should be equally considered for design purposes.

During a tsunami-induced inundation, horizontal forces $F_{x}$ are dominant in magnitude and their estimation is essential to properly design a structure. The purpose of this research is to describe the loading process of buildings subject to overtopping and to compare it to the corresponding case without overtopping. In addition, the effect of overtopping on the hydrodynamic load is described and quantified through an extensive experimental programme with a variety of different incident dry bed surges and wet bed bores. The main objectives of this study are:

- To provide an insight into the physical process for the overtopping of a free-standing building.
- To characterize the loading process for overtopped building in terms of horizontal forces, moments and impulse.

- To conclude whether the results presented and discussed by Wüthrich et al. (2018b) for impervious free-standing buildings can also be applied in case of overtopping.

\section{Previous studies}

The Japanese structural design guideline (SMBTR), developed by Okada et al. (2005), applies the findings of Asakura et al. (2000) based on the hydrostatic pressure distribution. As such, the design horizontal force $\left(F_{x, D}\right)$ is calculated using three times the incident wave height $h_{\max }$, resulting in Eq. (1):

$$
F_{x, D}=\frac{1}{2} \rho g B\left(3 h_{\max }\right)^{2}=9\left(\frac{1}{2} \rho g B h_{\max }^{2}\right)
$$

where $\rho$ is the water density $\left(\rho=1000 \mathrm{~kg} \mathrm{~m}^{-3}\right), g$ the gravity constant $\left(g=9.81 \mathrm{~m} \mathrm{~s}^{-2}\right), B$ the building width and $h_{\max }$ the maximum wave height. The same equation was also suggested by $\mathrm{CCH}$ (2000) and Okada et al. (2005). Equation (1) leads to a resultant force which is nine times the hydrostatic one; Yeh (2007) questioned its validity, as it presumably overestimates the actual value.

The issue of building overtopping was addressed by Nakano (2008), also based on the experimental results of Asakura et al. (2000). For the case with overtopping (Case 2 in Fig. 1), the same pressure value is assumed at the bottom of the structure; however, it is only applied to the actual height of the building, leading to Eq. (2):

$$
F_{x, D}=\frac{1}{2} \rho g B\left(6 h_{\max }-H_{B}\right) H_{B}
$$

where $\rho$ is the water density $\left(\rho=1000 \mathrm{~kg} \mathrm{~m}^{-3}\right), g$ the gravity constant $\left(g=9.81 \mathrm{~m} \mathrm{~s}^{-2}\right), B$ the building width, $h_{\max }$ the maximum wave depth and $H_{B}$ the building height. These findings are summarized in Fig. 1.

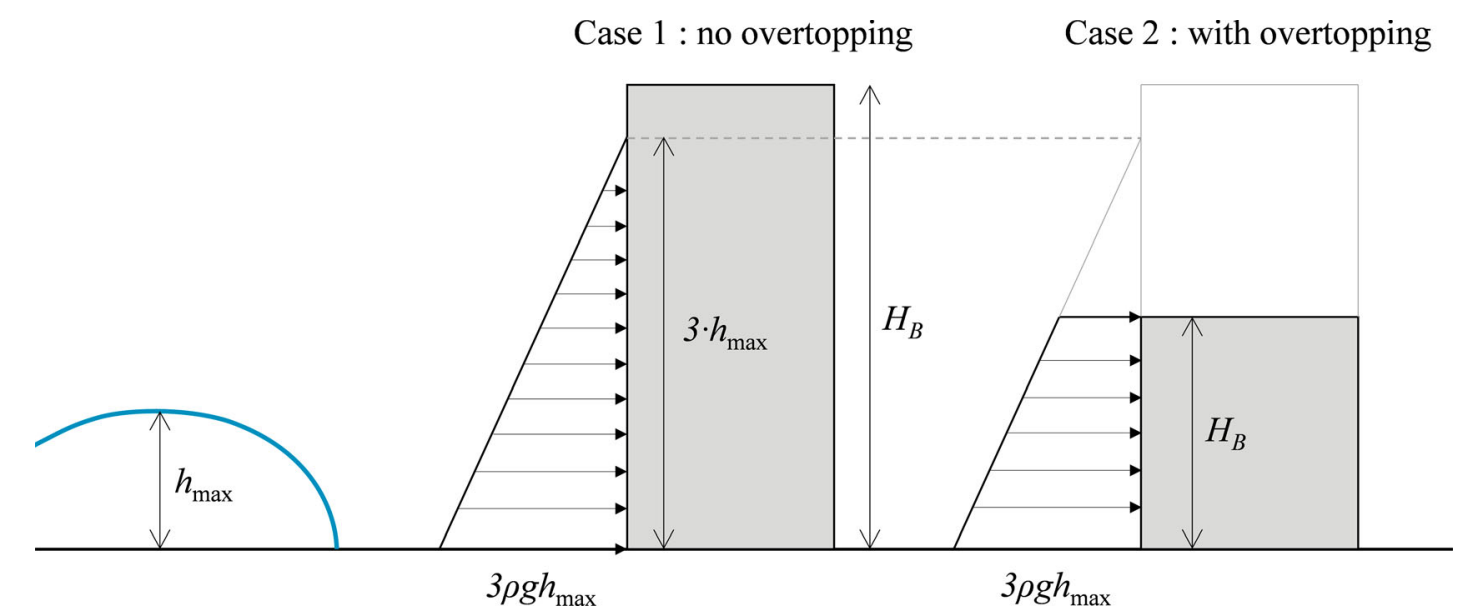

Figure 1 Forces with and without overtopping, according to Asakura et al. (2000) and Nakano (2008) 


\section{Experimental set-up}

\subsection{Wave generation}

The present study is based on an experimental approach and all tests were carried out at the Laboratory of Hydraulic Constructions ( $\mathrm{LCH})$ at Ecole Polytechnique Fédérale de Lausanne (EPFL), Switzerland. Both dry bed surges and wet bed bores were generated using a vertical release technique, as previously presented and discussed by Wüthrich et al. (2018a). Similar generation techniques were used by Chanson, Aoki, and Maruyama (2002), Rossetto, Allsop, Charvet, and Robinson (2011), Meile, Boillat, and Schleiss (2011) and Wüthrich et al. (2018b, 2018c). The experimental set-up is presented in Fig. 2. An upper reservoir with a volume of $7.1 \mathrm{~m}^{3}$ was linked to a water-filled lower reservoir through three identical and independent pipes. Each pipe was fitted with a valve and the sudden water release was achieved through a system of pulleys and ropes. When the system was activated, the water from the upper reservoir started flowing into the lower tank and, subsequently, into the channel. All waves propagated over a smooth horizontal channel with a length of $15.5 \mathrm{~m}$ and a width of $1.4 \mathrm{~m}$. On average, using steady-state experiments under various flow conditions, the Darcy-Weisbach friction factor of the channel was measured to be 0.02 . The water was evacuated at the downstream end of the flume through a vertical drain, thus avoiding any backwater effect. For the generation of wet bed bores, an initial still water depth $\left(h_{0}\right)$ on the flume ("wet bed" condition) was achieved using a variable vertical sill located at the downstream end of the channel.

The generated waves were shown to be similar to the classical dam-break waves (Wüthrich et al., 2018a). Unlike the use of solitary waves, dam-break waves are now considered a more appropriate technique to reproduce tsunami-like flows propagating inland (Chanson 2006; Madsen, Fuhrman, \& Schäffer, 2008; Nistor, Palermo, Nouri, Murty, \& Saatcioglu, 2009; Nouri et al.,
2010; Yeh, Liu, \& Synolakis, 1996). Dry bed surges and wet bed bores were proven to be similar to the Ritter (1892) and Stoker (1957) analytical solutions, respectively (Wüthrich et al., 2018a).

The openings of the valves resulted in a relatively constant discharge into the channel, and a quasi-constant water level was observed in the channel inlet (US1, $x=2 \mathrm{~m}$ ). As explained by Wüthrich et al. (2018a), this allowed an equivalent impoundment water depth $d_{0}$ to be computed, allowing a comparison with the classical dam-break generation mechanism (Fig. 1, Table 1). The good repeatability of the spatial and temporal features of the generated waves was verified and confirmed by Wüthrich (2018).

\subsection{Instrumentation}

The propagating waves and the impact were investigated using seven ultrasonic distance sensors (US) type Baumer UNAM $30 \mathrm{I6103}$ (Frauenfeld, TG, Switzerland), with a measuring range of the water depth between 100 to $1000 \mathrm{~mm}$. Water levels were sampled with an accuracy of $0.5 \mathrm{~mm}$ and a response time of less than $80 \mathrm{~ms}$. Their location is shown in Fig. 2. Among these, five sensors were located along the longitudinal axis of the channel at a distance $x=2.00,10.10,12.10$, 13.35 , and $13.85 \mathrm{~m}$ from the flume inlet, i.e. the downstream edge of the lower basin; one sensor was located on the roof of the structure to measure any potential overtopping (US6) and another sensor was located at the same location as the US7 $(x=13.85 \mathrm{~m})$ on the left hand side, at $y / W=-0.25$, where $y$ is the transversal coordinate and $W$ the channel width. An additional sensor (US0) with an extended measuring range (UNAM 50, 250-4000 mm) was installed in the upper reservoir to ensure the accurate recording of the valve opening time.

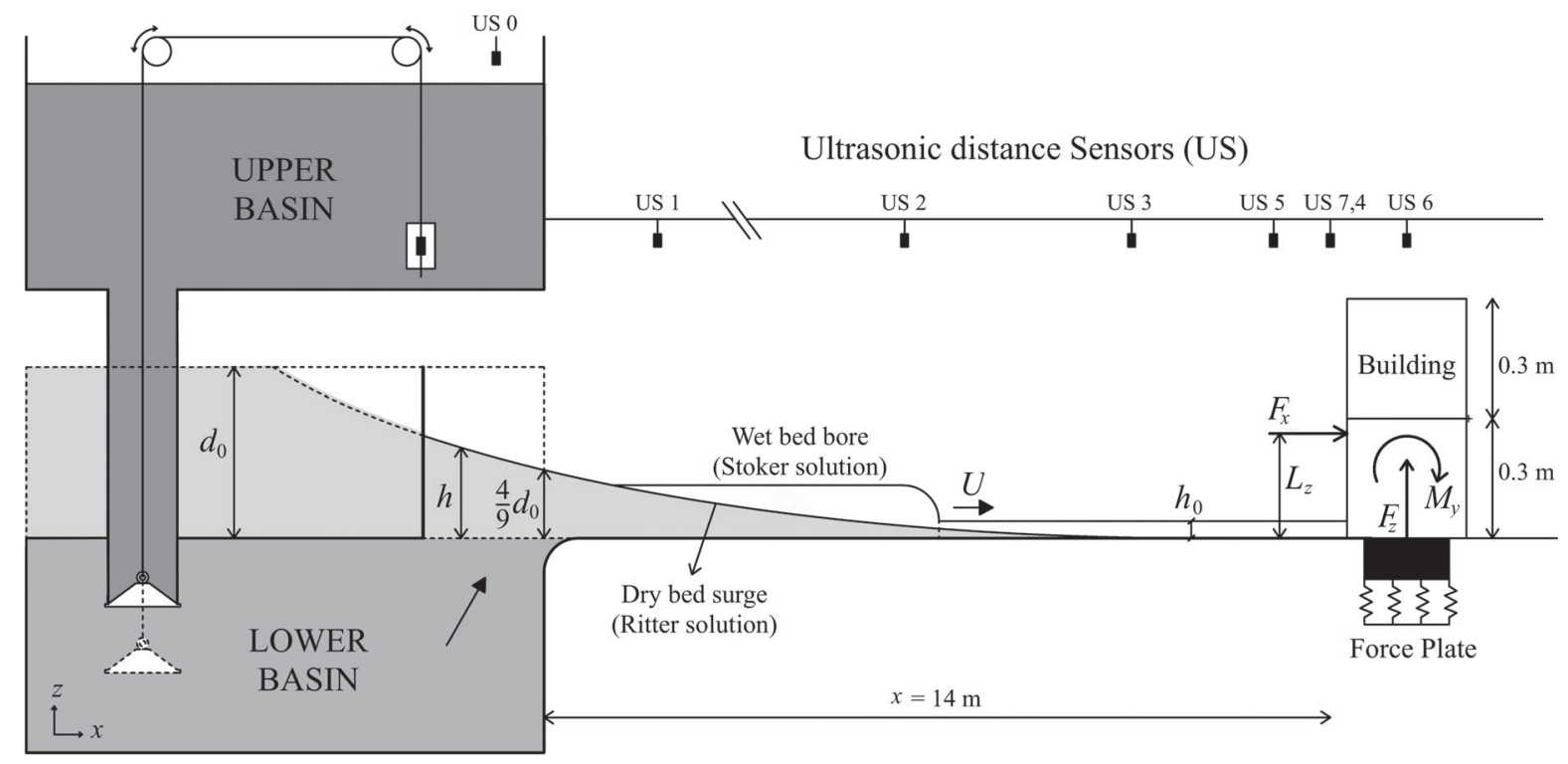

Figure 2 Experimental set-up used to generate bores and surges with the vertical release technique 
Table 1 Experimental programme

\begin{tabular}{|c|c|c|c|c|c|c|c|c|c|}
\hline \multirow[b]{2}{*}{ Building } & \multicolumn{7}{|c|}{ Wave characteristics } & \multirow[b]{2}{*}{ Repetitions } & \multirow[b]{2}{*}{ Test no. } \\
\hline & Bed & $d_{0}(\mathrm{~m})$ & $h_{0}(\mathrm{~m})$ & $U\left(\mathrm{~m} \mathrm{~s}^{-1}\right)$ & $h_{\max }(\mathrm{m})$ & $h_{0} / h_{\max }$ & Overtopping & & \\
\hline \multirow[t]{12}{*}{$H_{B}=0.3 \mathrm{~m}$} & Dry & 0.82 & 0 & 3.56 & 0.181 & 0 & Major & 2 & Test 1 \\
\hline & & 0.63 & 0 & 3.11 & 0.162 & 0 & Minor & 2 & Test 2 \\
\hline & & 0.40 & 0 & 2.35 & 0.132 & 0 & No & 2 & Test 3 \\
\hline & Wet & 0.82 & 0.010 & 3.07 & 0.193 & 0.052 & Major & 5 & Test 4 \\
\hline & & & 0.030 & 2.81 & 0.232 & 0.129 & Major & 4 & Test 5 \\
\hline & & & 0.050 & 2.75 & 0.260 & 0.193 & Major & 2 & Test 6 \\
\hline & & 0.63 & 0.010 & 2.70 & 0.172 & 0.058 & Minor & 2 & Test 7 \\
\hline & & & 0.030 & 2.52 & 0.206 & 0.146 & Minor & 3 & Test 8 \\
\hline & & & 0.050 & 2.44 & 0.224 & 0.223 & Minor & 2 & Test 9 \\
\hline & & 0.40 & 0.010 & 2.10 & 0.142 & 0.072 & No & 4 & Test 10 \\
\hline & & & 0.030 & 1.97 & 0.162 & 0.185 & No & 2 & Test 11 \\
\hline & & & 0.050 & 1.93 & 0.178 & 0.280 & No & 2 & Test 12 \\
\hline \multirow[t]{9}{*}{$H_{B}=0.6 \mathrm{~m}$} & Dry & 0.82 & 0 & 3.56 & 0.181 & 0 & No & 2 & Test 13 \\
\hline & & 0.63 & 0 & 3.11 & 0.162 & 0 & No & 2 & Test 14 \\
\hline & & 0.40 & 0 & 2.35 & 0.132 & 0 & No & 1 & Test 15 \\
\hline & Wet & 0.82 & 0.010 & 3.07 & 0.193 & 0.052 & No & 2 & Test 16 \\
\hline & & & 0.030 & 2.81 & 0.232 & 0.129 & No & 2 & Test 17 \\
\hline & & & 0.050 & 2.76 & 0.260 & 0.193 & No & 2 & Test 18 \\
\hline & & 0.63 & 0.010 & 2.70 & 0.172 & 0.058 & No & 1 & Test 19 \\
\hline & & & 0.030 & 2.52 & 0.206 & 0.146 & No & 1 & Test 20 \\
\hline & & & 0.050 & 2.44 & 0.224 & 0.223 & No & 1 & Test 21 \\
\hline Min & & 0.40 & 0 & 1.93 & 0.132 & 0 & - & 1 & - \\
\hline Max & & 0.82 & 0.050 & 3.56 & 0.260 & 0.280 & - & 5 & - \\
\hline
\end{tabular}

Note: $d_{0}=$ equivalent impoundment depth for dam-break analogy, $h_{0}=$ initial still water depth, $U=$ wave front celerity, $h_{\max }=$ maximum wave height measured without the building.

As shown in Fig. 2, the building models were installed on top of a force plate (AMTI MC6-1000) which recorded the time-history of the impact forces and moments, including surge and drag components, with an acquisition frequency of $1 \mathrm{kHz}$. Forces and moments in all three directions were measured for all tested scenarios. A representation of the principal direction is presented in Fig. 2 and the reference system used herein assumes $F_{x}$ is positive in the flow direction. $F_{y}$ is positive towards the left if surfing the wave and $F_{z}$ is positive in the upward direction.

For the force plate, no calibration was necessary; however, a validation of the results provided was conducted (Wüthrich,
2018). In addition, some tests were carried out without the building installed in the channel. For all tests, the force plate was reset to zero before the arrival of the wave to guarantee the same initial conditions.

\subsection{Building model}

The tested buildings were located at a distance $x=14.00 \mathrm{~m}$ downstream of the channel inlet to ensure full development of the bores/surges. The buildings used in the present study are shown in Fig. 3 and had a width $B=0.3 \mathrm{~m}$, resulting into (a) $H_{B}=0.6 \mathrm{~m}$

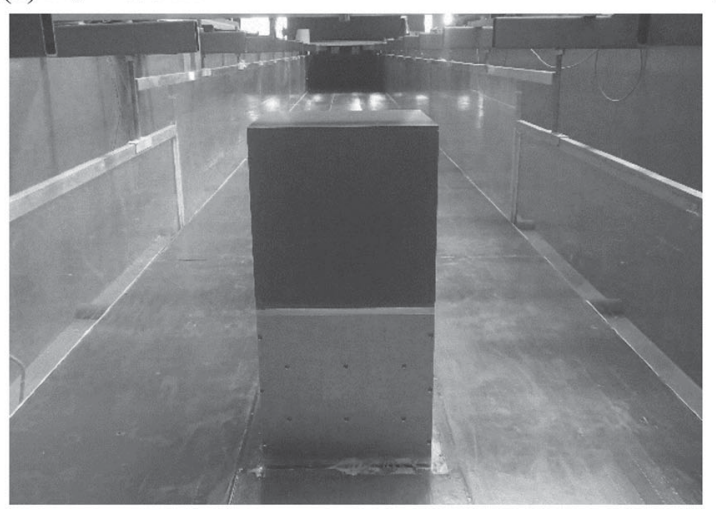

(b) $H_{B}=0.3 \mathrm{~m}$

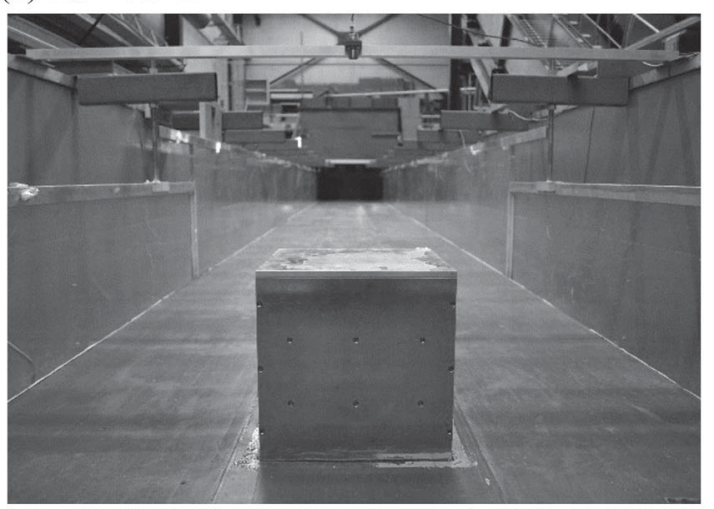

Figure 3 Impervious free-standing buildings: (a) $H_{B}=0.6 \mathrm{~m}$ without overtopping (Wüthrich et al., 2018b); (b) $H_{B}=0.3 \mathrm{~m}$, with overtopping for larger waves $\left(d_{0} \geq 0.63 \mathrm{~m}\right)$ 
a blockage ratio $\beta=W / B=4.67$; this value was sufficiently high to limit side wall effects and consistent with previous studies (Table 1). The buildings were in the form of aluminium cubes with a wall thickness of $10 \mathrm{~mm}$ and were designed to be completely rigid, ensuring that the building's dynamic response could be neglected. These structures represented buildings with height and width of $9 \mathrm{~m}$ if a Froude scaling ratio of 1:30 is assumed, corresponding to residential houses commonly observed in coastal zones exposed to tsunami hazard. Two building heights were tested herein: the first one, with a height $H_{B}=0.3 \mathrm{~m}$ represents a structure that might be overtopped during a flood and $H_{B}=0.6 \mathrm{~m}$ the impervious vertical shelters previously described by Wüthrich et al. (2018b).

The natural frequencies of both structures were found through Fourier fast transforms (FFT) of the horizontal force $F_{x}$. For the taller structure, with $H_{B}=0.6 \mathrm{~m}$, a value of $33 \mathrm{~Hz}$ was obtained. For the lower structure $H_{B}=0.3 \mathrm{~m}$, the frequency was around $45 \mathrm{~Hz}$. These values are within the same range as those identified by Arnason et al. (2009), Nouri et al. (2010) and Wüthrich et al. (2018b, 2018c) for similar free-standing buildings.

\section{Experimental methodology}

The present study is based on an experimental approach which included 46 tests for various waves with different hydrodynamic properties in terms of water depths and front celerity. Details of the experimental programme are presented in Table 1 for both scenarios: with and without overtopping. All parameters concerning the wave without the presence of the buildings were obtained as average values of multiple tests. The maximum model wave height $h_{\max }$ was $0.18 \mathrm{~m}$ for the dry bed surge and $0.26 \mathrm{~m}$ for the wet bed bore, with a front celerity $U$ ranging from 1.93 to $3.55 \mathrm{~m} \mathrm{~s}^{-1}$. For a Froude scaling ratio of 1:30, these values corresponded to a wave height of 5.5 to $8 \mathrm{~m}$ and a propagating celerity between 10.7 and $19.4 \mathrm{~m} \mathrm{~s}^{-1}$, which is consistent with field observations (Chock, Robertson, Kriebel, Francis, \& Nistor, 2012; Fritz et al., 2012; Jaffe et al., 2012).

As suggested by Bullock, Crawford, Hewson, Walkden, and Bird (2001) for the case of fully aerated flows, a Froude similitude was used herein. Reynolds numbers were large enough to ensure a sufficient level of turbulence of the flow $\left(\mathrm{R}_{\mathrm{e}} \approx 10^{5}-10^{6}\right)$. Moreover, the Weber number $\mathrm{W}_{\mathrm{e}} \approx 30$ was consistent with similar studies (Fuchs, 2013) and higher than the critical value $\mathrm{W}_{\mathrm{e}}=10$ defined by Schüttrumpf and Oumeraci (2005) to avoid scale effects in case of wave overtopping and wave run-up.

\section{Visual observations}

\subsection{Surges and bores}

As shown by several authors, including Ramsden (1996), Nouri et al. (2010) and Wüthrich et al. (2018a), waves propagating on dry or wet bed have different physical properties. A dry bed surge (also called non-breaking bore) represents the first incoming wave of a tsunami. In contrast, a wet bed bore represents any following wave propagating on wet bed. Both scenarios have to be equally considered, because past studies showed that the maximum resulting force may not always be associated with the first incoming tsunami wave.

The difference in behaviour between surges and bores propagating on a smooth horizontal bed was investigated in previous studies, including those by Lauber and Hager (1998), Ramsden (1996), Chanson (2004) and Wüthrich et al. (2018a). Dry bed surges are characterized by a constant increase in water depth without front aeration, whereas bores present a turbulent aerated front propagating along the channel with a sudden rise in water depth (Fig. 4). Furthermore, surges are associated with higher front velocities, whereas bores have greater wave heights.

\subsection{Wave impact}

Visual observations showed that the physical difference between surges and bores resulted in slightly different behaviours during the impact against a free-standing building. For both of these cases, two main phases were recognized: a short, initial "impact phase" of the wave front, followed by a "hydrodynamic phase" during which the main body of the wave flows around the structure. These two phases are visually presented in Fig. 5, where the time evolution of the impact is presented through pictures taken at $T\left(g / d_{0}\right)^{0.5} \approx 0$ (impact with highest (a) Dry bed surge

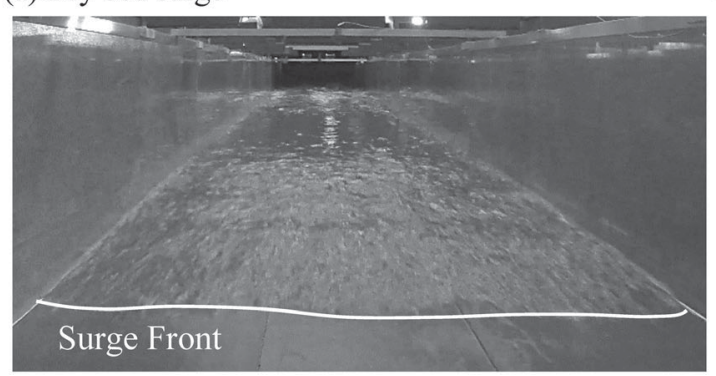

(b) Wet bed bore

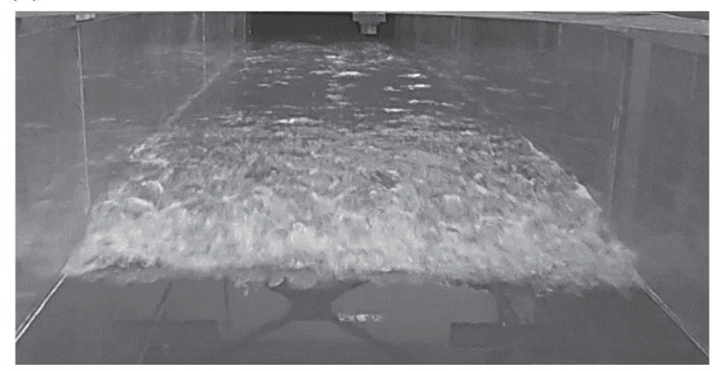

Figure 4 (a) Dry bed surge $\left(d_{0}=0.63 \mathrm{~m}, h_{\max }=0.162 \mathrm{~m}, U=3.11 \mathrm{~m} \mathrm{~s}^{-1}\right)$ and (b) wet bed bore $\left(d_{0}=0.63 \mathrm{~m}, h_{0}=0.03 \mathrm{~m}, h_{\max }=0.206 \mathrm{~m}\right.$, $U=2.52 \mathrm{~m} \mathrm{~s}^{-1}$ ), both generated with the vertical release technique 


$$
\begin{aligned}
& H_{B}=0.6 \mathrm{~m} \quad H_{B}=0.3 \mathrm{~m} \\
& d_{0}=0.82 \mathrm{~m} \text {, dry (test 13) } \quad d_{0}=0.82 \mathrm{~m}, h_{0}=0.05 \mathrm{~m} \text { (test 18) } d_{0}=0.82 \mathrm{~m} \text {, dry (test 1) } \quad d_{0}=0.82 \mathrm{~m}, h_{0}=0.05 \mathrm{~m} \text { (test 6) }
\end{aligned}
$$
(a) $T \cdot\left(g / d_{0}\right)^{0.5} \approx 0$
(b) $T \cdot\left(g / d_{0}\right)^{0.5} \approx 0$
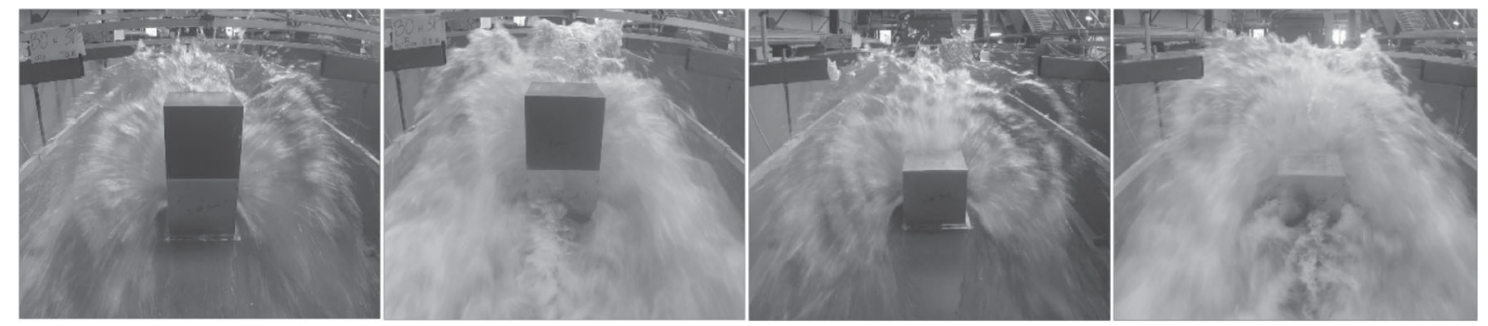

(e) $T \cdot\left(g / d_{0}\right)^{0.5} \approx 14$

(f) $T \cdot\left(g / d_{0}\right)^{0.5} \approx 14$

(g) $T \cdot\left(g / d_{0}\right)^{0.5} \approx 14$

(h) $T \cdot\left(g / d_{0}\right)^{0.5} \approx 14$
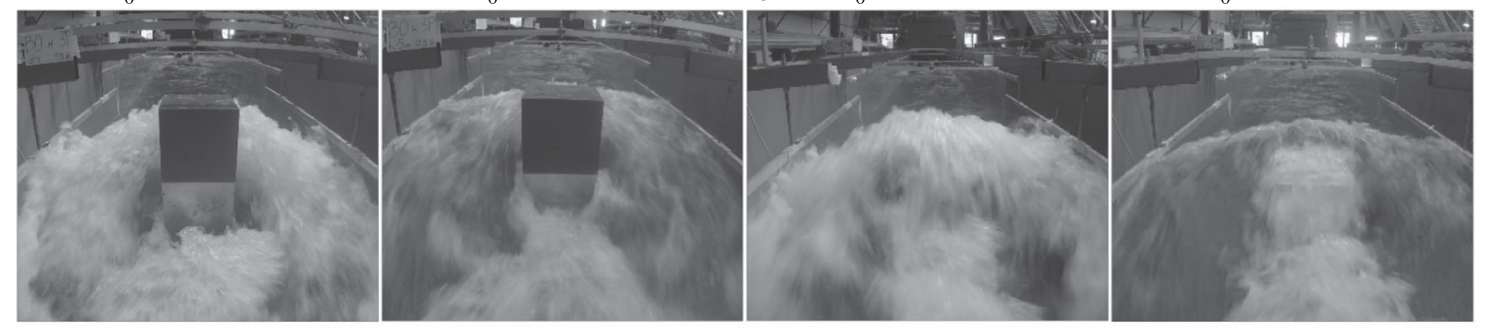

(i) $T \cdot\left(g / d_{0}\right)^{0.5} \approx 28$

(j) $T \cdot\left(g / d_{0}\right)^{0.5} \approx 28$

(k) $T \cdot\left(g / d_{0}\right)^{0.5} \approx 28$

(1) $T \cdot\left(g / d_{0}\right)^{0.5} \approx 28$
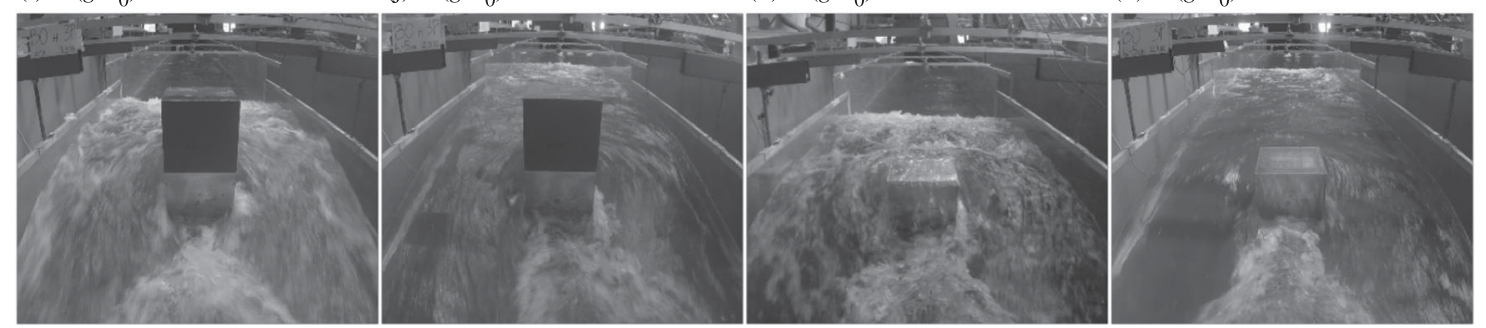

Figure 5 Time evolution of the wave impact against an impervious free-standing building for a dry bed surge $\left(h_{\max }=0.187 \mathrm{~m}, d_{0}=0.82 \mathrm{~m}\right)$ and a wet bed bore $\left(h_{\max }=0.269 \mathrm{~m}, d_{0}=0.82 \mathrm{~m}, h_{0}=0.05 \mathrm{~m}\right)$ for $H_{B}=0.3 \mathrm{~m}(\mathrm{c}, \mathrm{d}, \mathrm{g}, \mathrm{h}, \mathrm{k}, \mathrm{l})$ and $H_{B}=0.6 \mathrm{~m}(\mathrm{a}, \mathrm{b}, \mathrm{e}, \mathrm{f}, \mathrm{i}, \mathrm{j})$

run-up) and $T\left(g / d_{0}\right)^{0.5} \approx 14$ and 28 (post-impact hydrodynamic phase) for both surges and bores with and without overtopping. Note that in this study $T=0 \mathrm{~s}$ represent the wave arrival time at the measurement location and thus coincides with the instant of initial impact on the building. Similar results were previously presented by Wüthrich, Pfister, and Schleiss (2016), pointing out some key differences between the impact characteristics of surges and bores.

During the initial impact phase, no major differences were observed for the case with and without overtopping, i.e. $H_{B}=0.3 \mathrm{~m}$ and $H_{B}=0.6 \mathrm{~m}$, respectively. When the wave front hit the building's upstream side, a vertical run-up height $H$ was observed. This was measured to be some four times the maximum wave height without the presence of the structure $h_{\max }$ (Fig. 6). For both surges and bores, the impact phase was characterized by significant splashes and turbulent air entrainment on the upstream side of the building, as shown in Fig. 5a and $5 \mathrm{~d}$. Due to the presence of the building, the run-up splash fell back onto the incoming wave, producing a steady roller on the upstream side of the building, associated with high level of turbulence and air entrainment. The formation of the roller in the upstream side is shown in Fig. 5e and $5 \mathrm{f}$ and it marked the transition between the impact and the hydrodynamic phase. Visually, dry bed surges presented more aeration than wet bed bores, as shown in Fig. 5e,g and 5f,h. This is probably due to the higher velocities and Froude numbers associated with the incoming surge (Wüthrich et al., 2018a). Dry bed surges were also characterized by a pulsating behaviour, attributed to the interaction between the high-speed incoming wave and the reflection of the vertical run-up.

For the higher building $\left(H_{B}=0.6 \mathrm{~m}\right)$, no overtopping was observed and the water flowed only around the obstacle. For the lower building $\left(H_{B}=0.3 \mathrm{~m}\right)$ an overtopping of the building was observed for the largest waves $\left(d_{0}=0.63\right.$ and $\left.0.82 \mathrm{~m}\right)$. The higher flow velocities associated with the dry bed surge produced an aerated jet overpassing the structure (Fig. 5g), whereas for the bore a non-aerated flow submerging the building was observed (Fig. 5h). Visually, the overtopping seemed more important for bores.

For all scenarios, the presence of the building provoked a constriction, with an upstream decrease in flow velocity and an increase in water level. The combination of these effects led to a change in flow regime and to the propagation of a bore in upstream direction. For all configurations, intense vortices were observed downstream of the building for both the surge and the bore (Fig. 5). 
(a) Dry bed surge

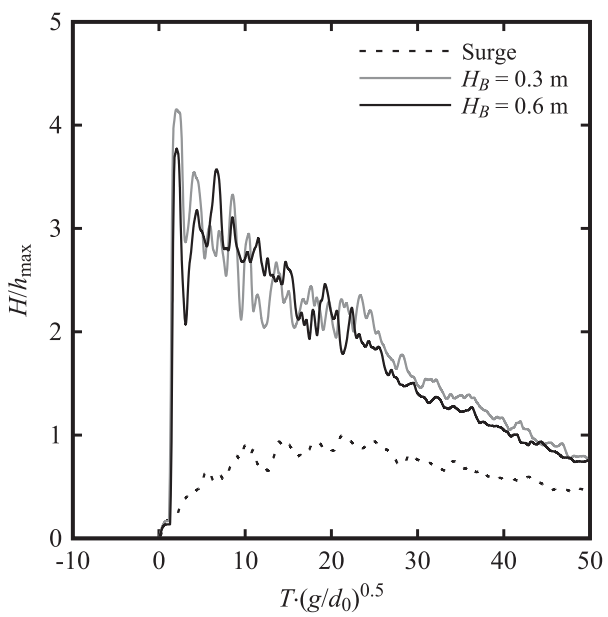

(b) Wet bed bore

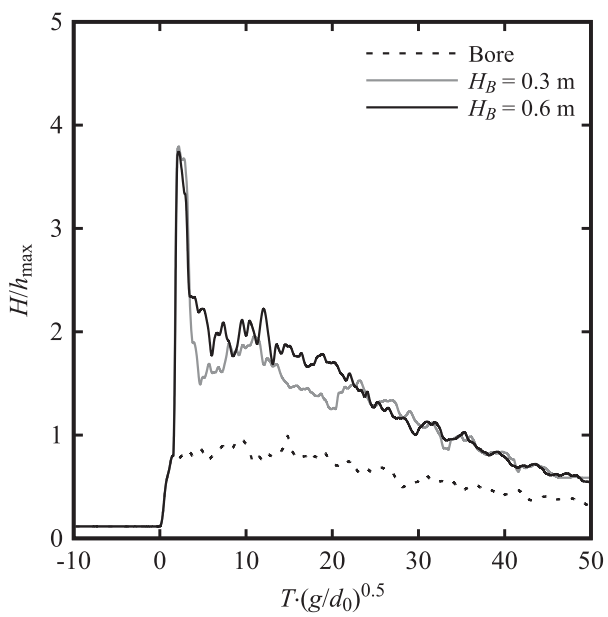

Figure 6 Profiles measured at US 7 for: (a) dry bed surge $\left(d_{0}=0.82 \mathrm{~m}, h_{\max }=0.162 \mathrm{~m}\right.$, test 13$)$; (b) wet bed bore $h_{0}=0.03 \mathrm{~m}\left(d_{0}=0.82 \mathrm{~m}\right.$, $h_{0}=0.03 \mathrm{~m}, h_{\max }=0.162 \mathrm{~m}$, test 17$)$

The ultrasonic distance sensor (US7) located $0.15 \mathrm{~m}$ upstream the building side (Fig. 2) measured the vertical runup heights, $H$, providing a quantitative description of the visual observations previously discussed. These results are shown in Fig. 6 for both a dry bed surge and a wet bed bore, with and without overtopping. These are also compared with the wave profile $h$ measured without the building. These measurements, although influenced by flow aeration and occasional splashes, show the difference in terms of flow characteristics between surges and bores. This confirmed a more fluctuating behaviour of the water surface for the case of flow propagating over an initially dry bed. For the dry bed surges, upstream water depths were similar, regardless of the building height $H_{B}$, whereas for bores, a higher discharge over the building resulted into a reduction of the sustained water depth on the upstream side.

(a)

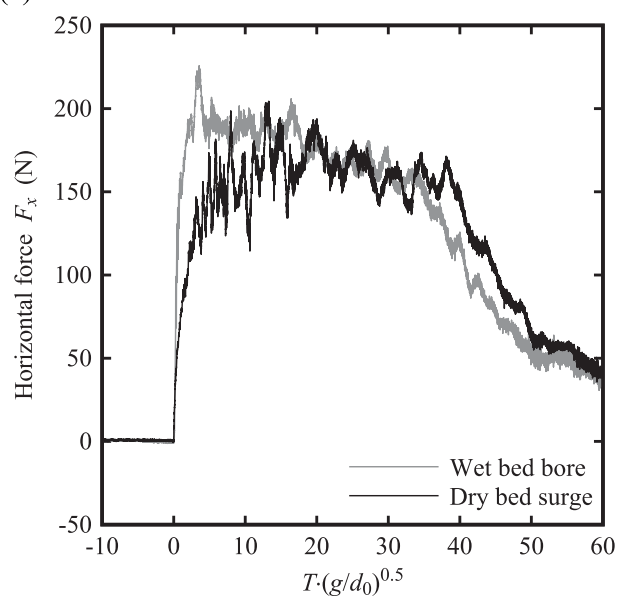

\section{Impact forces without overtopping}

Examples of the measurement obtained for horizontal force $F_{x}$ and the tilting moment $M_{y}$ for a dry bed surge and a wet bed bore are presented in Fig. 7. The magnitude of the forces and moments in the transversal $\left(F_{y}, M_{x}\right)$ and vertical directions $\left(F_{z}, M_{z}\right)$ was negligible compared to those observed in the flow direction $\left(F_{x}, M_{y}\right)$. For this reason, the values of $F_{y}, F_{z}, M_{x}$ and $M_{z}$ will be hereafter neglected. These features are similar to those previously observed by Ramsden (1996), Arnason et al. (2009) and Nouri et al. (2010). For the same release conditions $\left(d_{0}=0.63 \mathrm{~m}\right)$, similar maximum values were obtained for both the dry bed surges and the wet bed bores. Thus, bores are characterized by a sudden rise in horizontal force $F_{x}$ and moment $M_{y}$, whereas surges are associated with milder loading conditions.

(b)

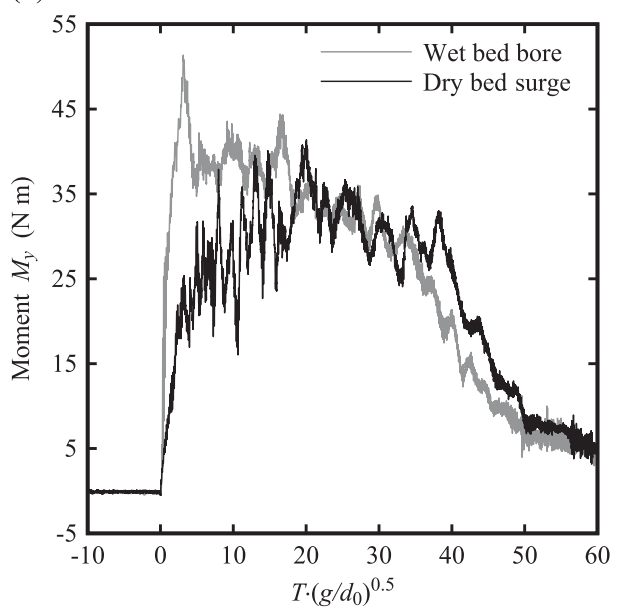

Figure 7 Loading scenario in terms of (a) horizontal forces $F_{x}$ and (b) tilting moment $M_{y}$, for both a dry bed surge $\left(d_{0}=0.63 \mathrm{~m}\right.$, test 14$)$ and a wet bed bore $\left(d_{0}=0.63 \mathrm{~m}, h_{0}=0.03 \mathrm{~m}\right.$, test 20$)$ without overtopping $\left(H_{\mathrm{B}}=0.6 \mathrm{~m}\right)$ 
Wüthrich et al. (2018b, 2018c) showed the validity of the following equations to compute the hydrodynamic load $F_{x}$ for similar buildings, without overtopping.

For surges:

$$
F_{x, D}=\frac{1}{2} \rho C_{R} B M=\frac{1}{2} \rho C_{R} B\left(h V_{m}^{2}\right)
$$

For bores:

$$
F_{x, D}=\frac{1}{2} \rho C_{R} B M^{*}=\frac{1}{2} \rho C_{R} B\left\{h\left[\min \left(\chi U ; V_{m}\right)\right]^{2}\right\}
$$

where $\rho$ is the water density $\left(\rho=1000 \mathrm{~kg} \mathrm{~m}^{-3}\right), B$ is the building width, $h$ is the wave height measured without the building, $U$ is the wave front celerity, and $V_{m}$ is the depth-averaged profile velocity defined by Wüthrich et al. (2018a) as a function of the impoundment depth, $d_{0}$, for a classical dam-break wave. For wet bed bores, an overestimation of the computed force was observed in the aerated front region. The maximum force was shown to be proportional to the modified maximum momentum flux per unit width $M_{\max }^{*}$ for both surges and bores through a wet bed bore reduction coefficient $\chi$ introduced by Wüthrich et al. (2018b). For hydrodynamic flows, an important role is played by the drag coefficient $C_{D}$. Similarly to Gupta and Goyal (1975) and Arnason et al. (2009), a resistance coefficient $C_{R}$, taking into account the impact, hydrostatic and hydrodynamic components was used herein. This was shown to be $C_{R}=2.0$ for impervious structures without overtopping.

$$
F_{x, D, \max }=\frac{1}{2} \rho C_{R} B M_{\max }^{*}
$$

\section{Effect of building overtopping}

As presented in Table 1, two scenarios were tested herein: building with a height $H_{B}=0.6$, where no overtopping was observed for any of the waves, and building with a height $H_{B}=0.3 \mathrm{~m}$, where some overtopping was observed for larger waves $\left(d_{0} \geq 0.63 \mathrm{~m}\right)$. For the smaller waves $\left(d_{0}=0.40 \mathrm{~m}\right)$, for both configurations, no overtopping was observed, showing good agreement with the findings of Wüthrich et al. (2018b). Some minor overtopping was observed for $d_{0}=0.63 \mathrm{~m}$ while major overtopping was recorded for $d_{0}=0.82 \mathrm{~m}$.

In this study, force measurements showed that for both dry bed surges and wet bed bores, the values recorded for a building with overtopping were lower compared to the non-overtopped scenario. Figure 8 shows the loading behaviour of two buildings with different heights $\left(H_{B}=0.6\right.$ and $\left.0.3 \mathrm{~m}\right)$ under the impact of the same incoming dry bed surge $\left(h_{\max }=0.187 \mathrm{~m}\right.$, $U=3.556 \mathrm{~m} \mathrm{~s}^{-1}$, corresponding to tests 1 and 13). One can notice a similar magnitude for the force acting on both buildings during the first seconds of the impact. Some differences can be observed during the hydrodynamic phase of the impact, with the overtopped building (grey line) less loaded. Similar results are obtained for other dry bed surges (not shown). A similar case for a wet bed bore with an initial still water depth $h_{0}=0.03 \mathrm{~m}\left(h_{\max }=0.254 \mathrm{~m}, U=2.810 \mathrm{~m} \mathrm{~s}^{-1}\right.$, tests 5 and 17$)$ is presented in Fig. 9. Results showed that for the wet bed bore, the magnitude of the recorded forces in case of overtopping was lower than the scenario without overtopping. As compared to the dry bed surge shown in Fig. 8, the difference between the two scenarios is more significant for bores (Fig. 9).

Additionally, higher water levels were observed on the downstream side of the buildings for the scenarios with overtopping (Fig. 5m and 5n), contributing to a lower hydrostatic component in the total force. This was also identified by Esteban et al. (2017). The reduction in $F_{x \text {,max }}$ can be clearly observed in Fig. 10, where the forces recorded for the scenarios with overtopping over the building (empty symbols) are overestimated by the use of Eqs (3) and (4) if using the standard value of the resistance coefficient, $C_{R}=2.0$.

In addition, both Figs 8 and 9 show the behaviour of the force in the vertical direction $F_{z}$, representing the weight of the overtopping water (negative values indicate a force vector downwards, Fig. 2). Higher values of $F_{\mathrm{z}}$ are observed for the wet bed bore, confirming the visual observations and suggesting

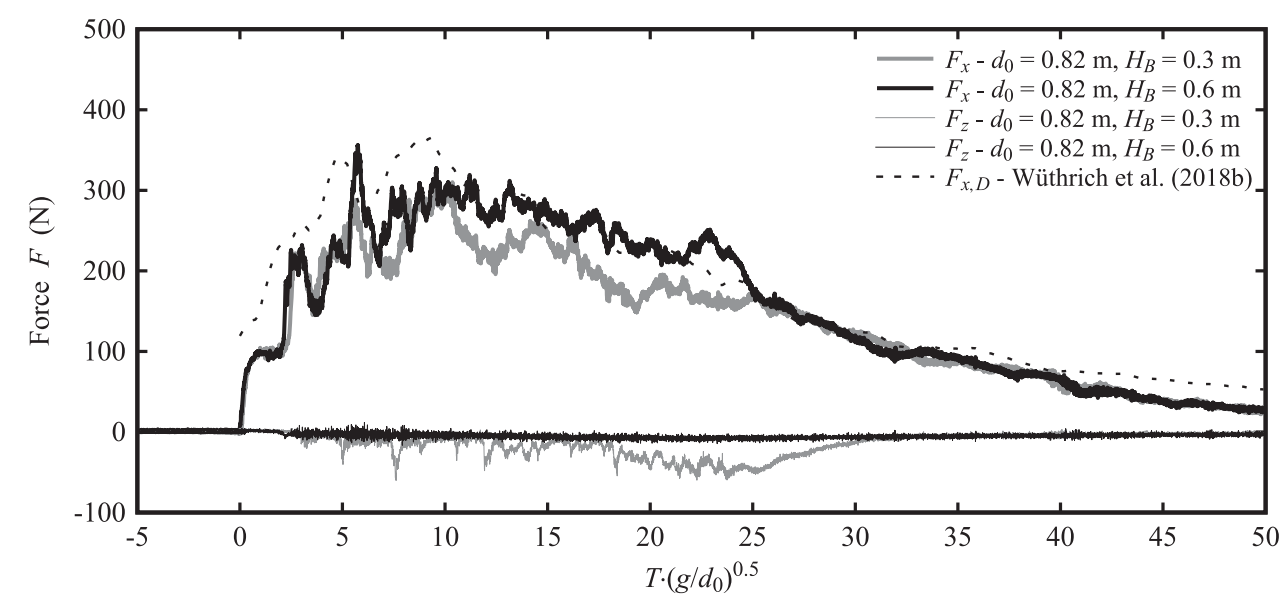

Figure 8 Time-history of the horizontal $\left(F_{x}\right)$ and vertical $\left(F_{z}\right)$ forces measured for a dry bed surge $\left(h_{\max }=0.187 \mathrm{~m}, U=3.556 \mathrm{~m} \mathrm{~s}{ }^{-1}\right)$ impacting an impervious structure with $\left(H_{B}=0.3 \mathrm{~m}\right.$, test 1$)$ and without $\left(H_{B}=0.6 \mathrm{~m}\right.$, test 13$)$ overtopping 


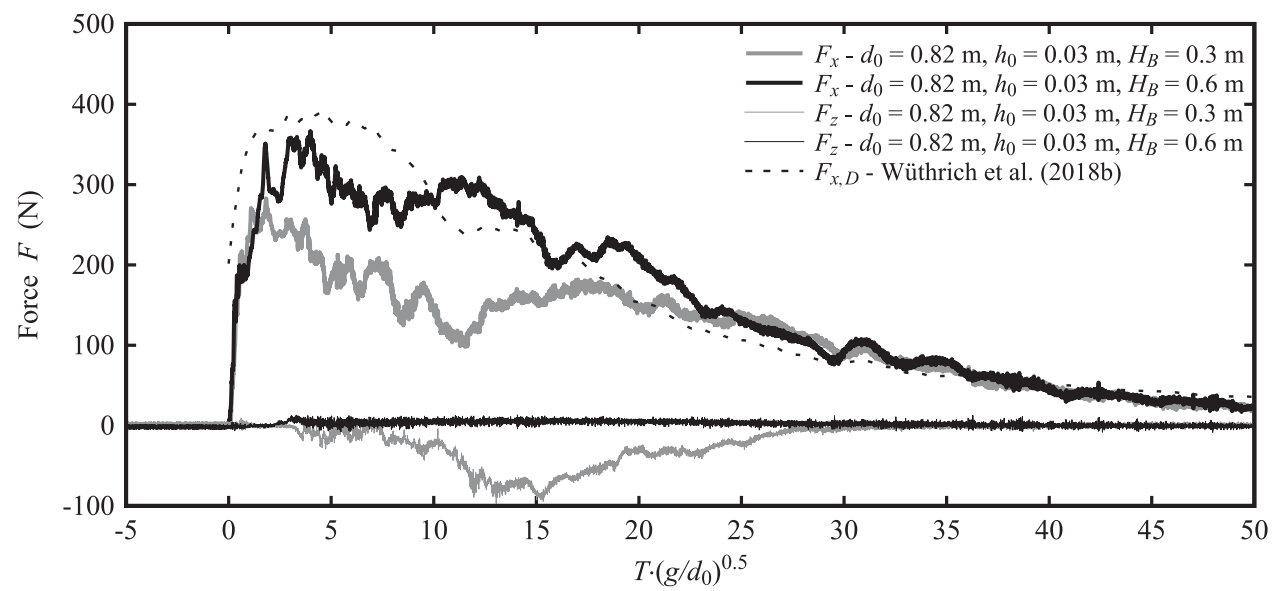

Figure 9 Time-history of the horizontal $\left(F_{x}\right)$ and vertical $\left(F_{z}\right)$ forces measured for a wet bed bore $\left(h_{\max }=0.23 \mathrm{~m}, h_{0}=0.03 \mathrm{~m}, U=2.81 \mathrm{~m} \mathrm{~s}{ }^{-1}\right)$ impacting an impervious building with $\left(H_{B}=0.3 \mathrm{~m}\right.$, test 5$)$ and without $\left(H_{B}=0.6 \mathrm{~m}\right.$, test 17) overtopping

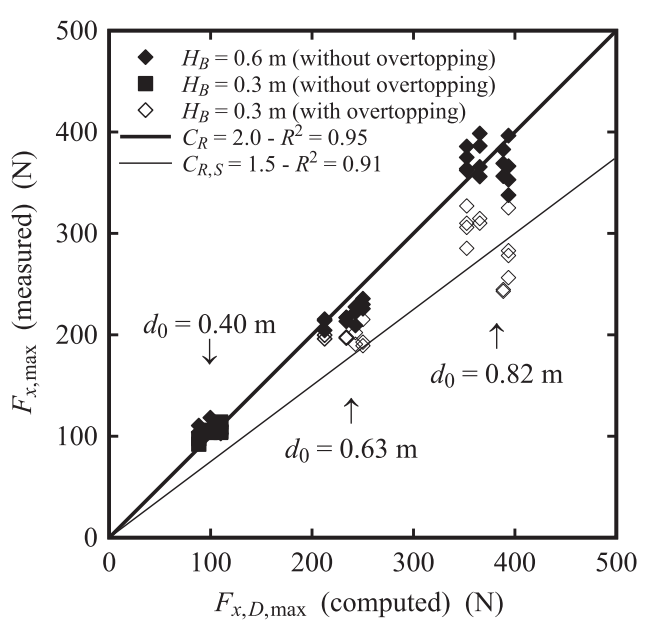

Figure 10 Comparison between measured and predicted force values for the configurations with overtopping $\left(C_{R, S}=1.5, R^{2}=0.91\right)$ and without overtopping $\left(C_{R}=2.0, R^{2}=0.95\right)$

a more important overtopping discharge (Fig. 5h). This higher discharge was responsible for the increased downstream water depth and thus, for the reduction of the horizontal force. For a dry bed surge, visual observations in Fig. $5 \mathrm{~g}$ showed an aerated jet overtopping the structure, a feature which might also be responsible for the lower vertical force measured by the force plate.

The authors conclude that a combination of a reduced upstream run-up height and an increased downstream water level are responsible for a lower horizontal force. In the calculation of the horizontal force, this translated in a reduced resistance factor $C_{R}$, as shown in Figs 10 and 11. Experimental data showed that for the scenarios with overtopping, a value $C_{R, S}=1.5$ was more appropriate, compared to the value $C_{R}=2.0$ used for buildings without overtopping. The better agreement found for a reduced resistance coefficient can be inferred from results shown in Fig. 11.

If Eqs (1) and (2) are used to estimate the design forces $F_{x, D}$, an overestimation of the measured force $F_{x}$ by a factor of 3 to 4 was found. This confirms the study of Yeh
(2007) questioning their validity for the design of free-standing impervious buildings with and without overtopping.

\subsection{Force analysis}

As previously performed by Wüthrich et al. (2018b), an indepth analysis of the horizontal forces presented in the previous sections is carried out in this section. The main parameters discussed are presented hereafter:

- "time to peak": the time from wave arrival to the moment when the force peak occurs, $\tau_{\max }$;

- relative wave height $h_{M}$ for which the maximum horizontal force is measured (at $\tau_{\max }$ ); and

- impulse $I$ transferred from the wave to the building.

Time to peak $\tau_{\max }$

The "time to peak" $\tau_{\max }$ represents the time interval between the moment of impact $(T=0)$ and the instant when the maximum measured horizontal force $F_{x \text {, max }}$ is recorded. The values of $\tau_{\max }$ measured for all tests are presented in dimensionless form in Fig. 12 as a function of $h_{0} / h_{\max }$, where $h_{0} / h_{\max }=0$ represents the dry bed surges and $h_{0} / h_{\max }>0$ represents the wet bed bores. Results show larger values of $\tau_{\max }$ up to $\tau_{\max } \sqrt{g / d_{0}}=30$, for dry bed surges $\left(h_{0} / h_{\max }=0\right)$, whereas for bores $\left(h_{0} / h_{\max }>0\right)$, almost all maximum forces occurred for $\tau_{\max }<5 \sqrt{d_{0} / g}$. These findings clearly showed that the maximum force occurred earlier for wet bed bores than for dry bed surges, a finding which is in agreement with the results of Wüthrich et al. (2018b). Results in Fig. 12 also show that the maximum time to peak occurred a little earlier for buildings with overtopping (void symbols), compared to the scenario without overtopping (filled-in symbols).

\section{Wave height recorded at the instant of maximum force}

A relevant parameter for the design of tsunami resistant buildings is the wave height $h$, at the instant when the maximum force $F_{x, \text { max }}$ occurs. This relative height $h_{M}$ is defined in Eq. (6) as the 

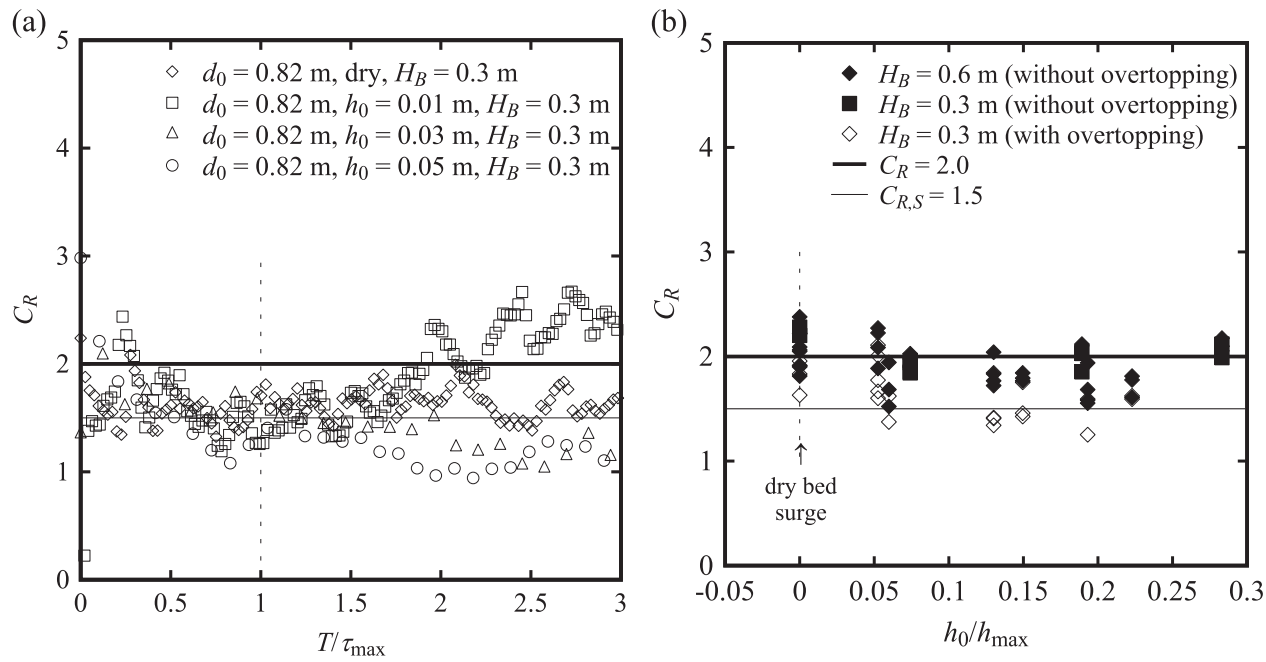

Figure 11 Variation of the resistance coefficient $C_{R}$ for buildings with $\left(H_{B}=0.3 \mathrm{~m}\right)$ and without $\left(H_{B}=0.6 \mathrm{~m}\right)$ overtopping for surges and bores: (a) time development before and after the occurrence of the maximum force $\left(T / \tau_{\max }=1\right)$; (b) values of $C_{R}$ when the maximum force takes place $\left(T / \tau_{\max }=1\right)$ as a function of $h_{0} / h_{\max }$

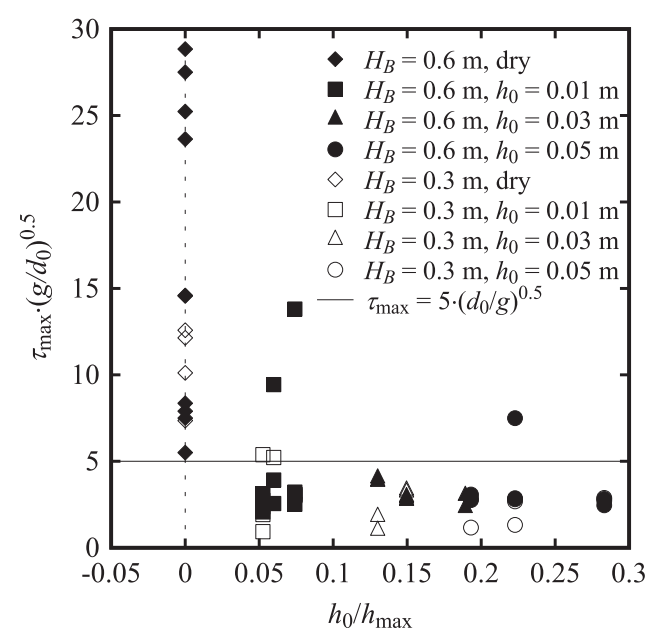

Figure 12 Time to peak $\left(\tau_{\max }\right)$ for both bores and surges with (void symbols) and without overtopping (filled-in symbols)

ratio between the wave height $h$ (measured without the building) at which the maximum force occurs $\left(T=\tau_{\max }\right)$, and the absolute maximum wave height $h_{\max }$ (also measured without the building in the flume, thus independent of the force development):

$$
h_{M}=\frac{h\left(T=\tau_{\max }\right)}{h_{\max }}
$$

The values of the relative wave heights obtained from the experimental tests are presented in Fig. 13. These values are also compared with those calculated using the prescriptions of the design guidelines from ASCE7-6 (2016), according to which the maximum hydrodynamic load occurs at $2 / 3$ of the maximum inundation height, i.e. when $h=2 / 3 h_{\max }$. The comparison showed good agreement for data corresponding to dry bed surges $\left(h_{0} / h_{\max }=0\right)$. However, for increasing values of $h_{0} / h_{\max }$, results seemed to indicate that the choice of $h_{M}=2 / 3$ becomes less conservative. Being the maximum force proportional to the

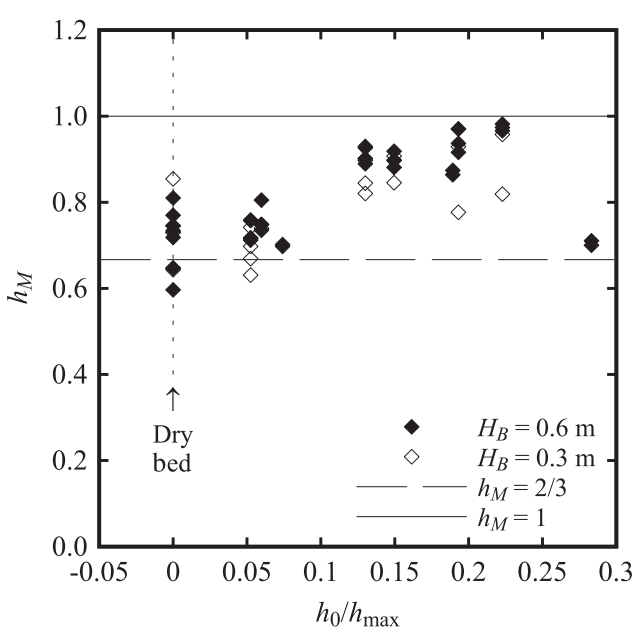

Figure 13 Relative wave height $h_{M}$ at which the maximum force $F_{x \text {,max }}$ occurs, and comparison with design recommendations from ASCE7-6 (2016)

maximum momentum in Eq. (5), these results are consistent with the findings of Wüthrich et al. (2018a) for the maximum momentum flux per unit width, $M$.

\section{Impulse I}

The product of force and time is commonly known as impulse, $I$. In this specific case, the total impulse $I_{\text {tot }}$ can be identified as the integral of the horizontal force, $F_{x}$, over time, until the upper limit $T=100 \cdot \sqrt{d_{0} / g}$ is reached. This value was chosen as it represents the shortest period able to capture all main features of the loading process for all tested configurations. The total impulse is thus defined by Eq. (7):

$$
I_{t o t}=\int_{0}^{100 \cdot \sqrt{\frac{d_{0}}{g}}} F_{x}(T) d T
$$


Mathematically, the impulse represents the area below the force-time curve (Wüthrich et al., 2018b). Given Newton's second law $(F=m \cdot a=m \cdot \Delta V / \Delta t)$, the impulse can be seen as $I=F \cdot \Delta t=m \cdot \Delta V$, corresponding to a change in momentum. The total impulse experienced by the building $I_{t o t}$, therefore equals the exchange in momentum between the incoming wave and the free standing building. Current results show that, if a building is overtopped $\left(H_{B}=0.3, d_{0}>0.63 \mathrm{~m}\right)$, less impulse will be transferred to the structure compared to the case with overtopping. As previously discussed in Section 6 and shown in Figs 8 and 9, this is a consequence of the smaller force magnitude recorded for the case of the overtopped building. In addition, from Fig. 14a, it seems that the impulse asymptotically stabilizes and that no difference is observed between the two largest tested impoundment depths.

To better define the amount of impulse that is transferred to the building before the occurrence of the peak, a parameter $I_{\text {peak }}$ is defined as the integral between the interval $0<T<\tau_{\max }$. This parameter represents the surface below the curve until $F_{x \text {,max }}$ is reached:

$$
I_{\text {peak }}=\int_{0}^{\tau_{\max }} F_{x}(T) d T
$$

Results for the total impulse and the peak impulse are presented in Fig. 14a for buildings with and without overtopping ( $H_{B}=0.3$ and $0.6 \mathrm{~m}$, respectively), showing similar results for both configurations. Figure $14 \mathrm{a}$ also shows that the impulse transferred before the occurrence of the force peak is only a small portion of its total magnitude. A parameter, $I^{*}$, can thus be defined as the ratio between the peak impulse $I_{\text {peak }}$ and the total impulse $I_{\text {tot }}$, corresponding to the amount of impulse that is recorded before the peak force occurs:

$$
I^{*}=\frac{I_{\text {peak }}}{I_{\text {tot }}}
$$

(a)

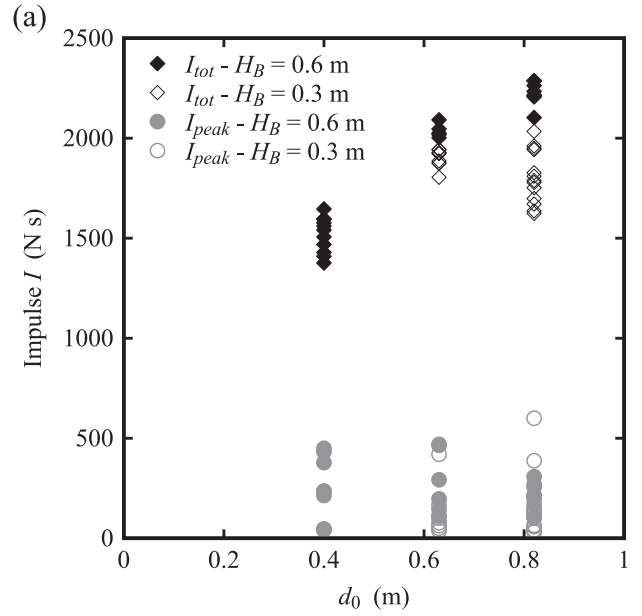

The values for the relative impulse are presented in Fig. 14b, where a difference in behaviour can be observed between surges and bores. For bores, less than $10-15 \%$ of the impulse is transferred to the building before the peak force occurs. For surges, however, this can reach $30-35 \%$. This difference is also a consequence of the time to peak values. These results are in agreement with those previously observed by Wüthrich et al. (2018b) for the case of impervious structures without overtopping and by Bullock, Obhrai, Peregrine, and Bredmose (2007), who found that $I_{\text {peak }}<0.3 \cdot I_{\text {tot }}$.

\subsection{Moment and cantilever arm}

Any force applied outside of its centre of gravity produces a moment that is directly proportional to the force's application distance, the cantilever $\operatorname{arm} L_{z}$. The moments are important for the stability of buildings, because they act toward their overturn. In this study, only moments in the transversal direction $\left(M_{\mathrm{y}}\right)$ were considered since the moment magnitude in the other two directions, $M_{x}$ and $M_{z}$ was negligible. Despite some scattering, results in Fig. 15 confirmed the approach of Wüthrich et al. (2018b) who showed that the maximum moment $M_{y \text {, max }}$ occurred simultaneously with the horizontal force $F_{x \text {, max }}$, even in case of building overtop.

Similarly to what was discussed in Section 6 for the magnitude of the horizontal forces, buildings without overtopping consistently showed moment values that were larger than those calculated for buildings with overtopping.

Once the maximum horizontal force is known, the momentum can be obtained through the cantilever arm $\left(L_{z}\right)$, which represents the distance from the reference point at which the force is applied. For the present study, the reference point $\left(L_{z}=0\right)$ coincides with the channel bottom, as shown in Fig. 2. Experimentally, the behaviour of $L_{z}$ in time can be computed as the ratio between moment around $y$-axis $M_{y}$ and the horizontal force $F_{x}$. Since both maximum force and moment occur at the

(b)

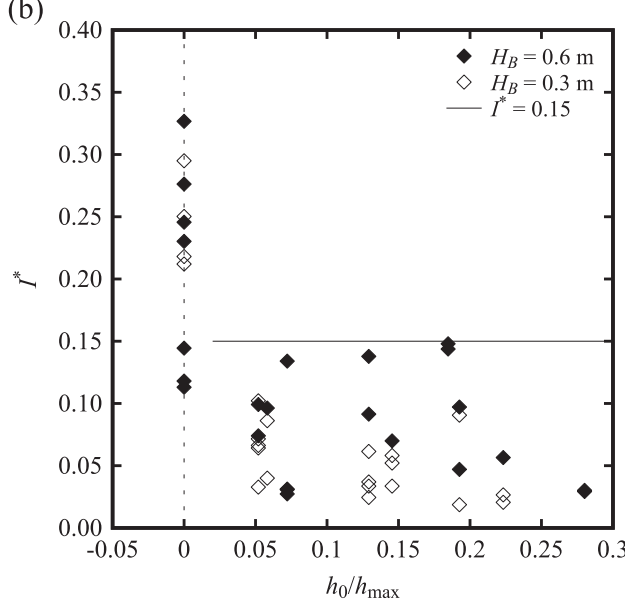

Figure 14 (a) Total impulse $\left(I_{t o t}\right)$ and peak impulse $\left(I_{\text {peak }}\right)$ measured for both the case of bores and surges with and without building overtopping. (b) Relative impulse $I^{*}=I_{\text {peak }} / I_{\text {tot }}$ for both dry bed surges and wet bed bores 


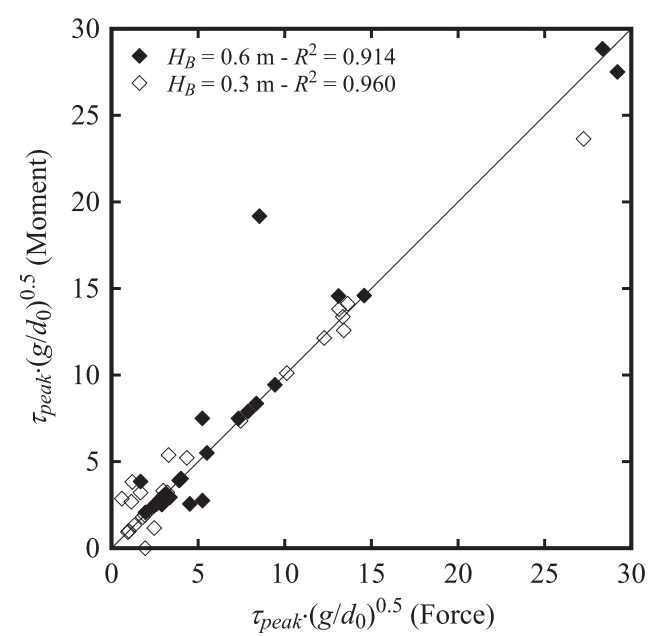

Figure 15 Time of occurrence of the maximum horizontal force $F_{x \text {,max }}$ and of the maximum moment $M_{y \text {, max }}$

same time, the cantilever arm at $T=\tau_{\max }$ can be obtained through Eq. (10):

$$
L_{z}\left(T=\tau_{\max }\right)=\frac{M_{y, \max }}{F_{x, \max }}
$$

The values derived from the experimental data are presented in Fig. 16 as a function of $h_{0} / h_{\max }$ for both dry bed surges and wet bed bores. These are also compared with values previously obtained for the impervious structure without overtopping $\left(H_{B}=0.6 \mathrm{~m}\right)$. All values are normalized using the maximum wave height $h_{\max }$ measured without the presence of the building.

Figure 16 shows that for all tests, the cantilever arm was almost constant around an average value of $1.00 h_{\max }$. It could therefore be assumed that, on average, the total horizontal force defined in Section 6 was applied at a height that corresponded to the maximum wave height $h_{\max }$ measured without the presence of the building. This allowed an equation to be obtained to compute the maximum moment $M_{y, D, \max }$ as a function of the

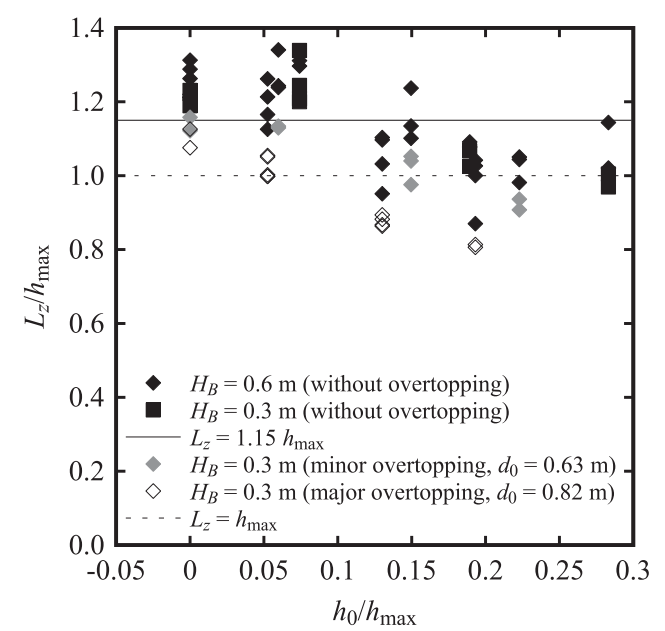

Figure 16 Cantilever arm $L_{z}$ computed for both dry bed surges $\left(h_{0} / h_{\max }=0\right)$ and wet bed bores $\left(h_{0} / h_{\max }>0\right)$ at time $T=\tau_{\max }$ (Table 1)

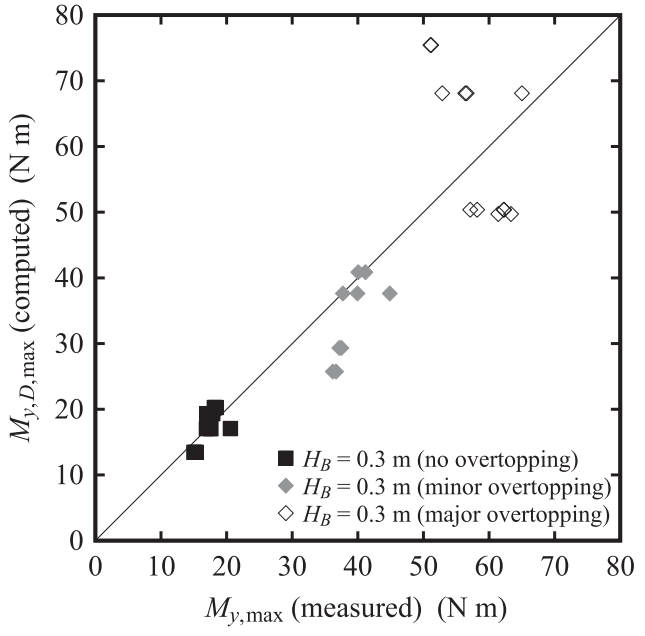

Figure 17 Comparison of maximum measured values $M_{y}$, max with those calculated using Eq. (11), $M_{y, D, \max }\left(R^{2}=0.76\right)$

hydrodynamic properties of the wave without the presence of the building:

$$
M_{y, D, \max }=1.00 h_{\max } F_{x, D, \max }=\frac{1}{2} \rho C_{\mathrm{R}, \mathrm{S}} B M_{\max }^{*} h_{\max }
$$

where $F_{x, D \text {, max }}$ is maximum horizontal force computed using Eq. (5) with a resistance coefficient $C_{R, S}=1.5$ which was defined in Section 6 for the scenarios with building overtopping. The magnitude of the maximum moment $M_{y \text {,max }}$ calculated using through Eq. (11) is compared with the experimental data in Fig. 17.

\section{Discussion}

Findings of the present study indicate that, when a building is overtopped, a reduction in both the force and the impulse is observed. This means that, from a structural point of view, a building which is overtopped is subject to milder loading conditions for a given flood wave, as compared to a higher building impacted by the same wave. The comparison with the results obtained in Section 6 shows that a modification of the resistance coefficient $C_{R}$ and the cantilever arm $L_{z}$ was appropriate to obtain a better approximation of the forces and moments, when referring to the basic hydrodynamic properties of the wave measured without the presence of the structure.

The overtopping depth was difficult to accurately obtain from the US sensors, as these were affected by air entrainment and run-up splashes. For this reason, an equivalent overtopping depth $H_{e q}$ was derived from the maximum vertical force $F_{z \text {,max }}$ measured by the force plate:

$$
H_{e q}=\frac{F_{z, \max }}{B^{2} g \rho}
$$

A value of $H_{e q}=0$ implies that no water passed over the building, whereas for $H_{e q}>0$ the building was overtopped. 
(a)

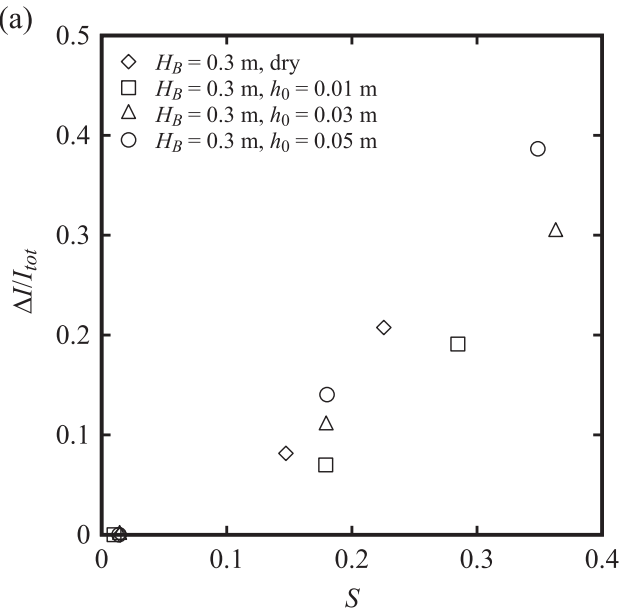

(b)

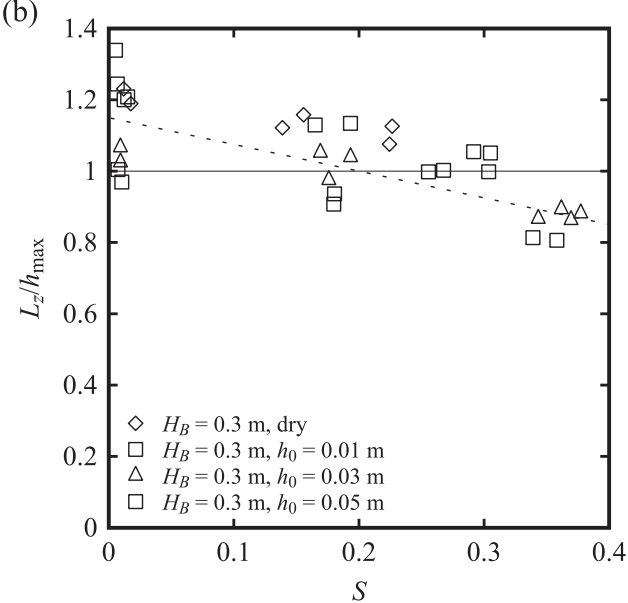

Figure 18 Dependence of: (a) impulse $\Delta I / I_{\text {tot }}$ and (b) cantilever arm $L_{z} / h_{\max }$ on the degree of overtopping of the building, described herein by the overtopping coefficient $S$, defined in Eq. (13)

Hereafter, the reduction in total impulse $\Delta I_{\text {tot }}$ due to the overtopping of the building is addressed. Accordingly, an overtopping coefficient $S$ is defined in Eq. (13) as the ratio between the equivalent overtopping depth $H_{e q}$ and the building height $H_{B}$ :

$$
S=\frac{H_{e q}}{H_{B}}=\frac{F_{z, \max }}{B^{2} g \rho H_{B}}
$$

If $S>0$, then some overtopping was observed, otherwise $S \approx$ 0 and no overtopping occurred. Figure 18a shows, for all tested waves, an increasing trend for the values of $\Delta I / I_{\text {tot }}$, where $\Delta I$ is the impulse reduction due to overtopping and $I_{t o t}$ the total impulse for the non-overtopped building. This proved that the reduction of the impulse is a function of the overtopping coefficient $S$ and therefore of the volume of water that overtopped the building. Similarly, the cantilever arm $L_{z}$ shown in Fig. 18b is proportional to the overtopping coefficient. Higher values of $S$ correspond to smaller horizontal forces, cantilever arms and, therefore, reduced moments. Nevertheless, the overtopping of a building is, generally, not a regular load condition to practical engineers and it cannot be hence deduced from the basic hydrodynamic properties of the wave. For this reason, loading conditions calculated using the proposed resistance coefficient $C_{R, S}=1.5$ and the cantilever arm $L_{z}=h_{\max }$ is shown to represent a good preliminary approach. It is also important to point out that in case of higher overtopping (values of $H_{B} / h_{\max }$ $<<1.5$ ), the magnitude of the resistance coefficient $C_{R, S}$ is expected to be smaller than 1.5 and further investigations are needed.

\section{Conclusions}

In coastal areas, some particular buildings, often associated with critical infrastructures, are designed as vertical evacuation shelters, whereas for others, overtopping is accepted. The experimental programme mainly focuses on low-rise buildings, potentially overtopped in case of extreme coastal flood events such as tsunami inundation. This issue was rarely addressed in the past. The results elaborated for these low-rise buildings were then compared with results from the study on the impervious free-standing buildings discussed by Wüthrich et al. (2018b). This study proposes a methodology to quantify the effect of building overtopping on the resulting wave-induced loads. This represents a preliminary approach in the design of coastal buildings prone to potential overtopping that could be applied to extreme flood events and inundation occurring in a built environment.

The following conclusions could be drawn:

(1) As a result of overtopping, higher water levels were observed on the downstream side of the building, as compared to the configuration without overtopping.

(2) In terms of hydrodynamic loading, buildings with overtopping were consistently subjected to lower horizontal forces and impulse compared to the buildings which were not overtopped. This is probably a consequence of the smaller difference in water depth between the upstream and the downstream building sides, which resulted in a reduced hydrostatic pressure component and thus a smaller force. Results also showed that, mostly for wet bed bores, the maximum force occurred slightly earlier for the buildings with overtopping compared to the scenario without overtopping. This modified dynamics of the buildings with overtopping also resulted in reduced cantilever arms, and, therefore, in smaller tilting moments.

(3) The formulae presented and discussed in Section 6 for buildings without overtopping (Eqs 3 and 5) can be applied to buildings potentially overtopped; however, these expressions lead to an overestimation of the forces. If a more precise estimation of the forces is desired, then a modified approach with a reduced resistance coefficient $C_{R, S}=1.5$ can be used. In addition, the resulting horizontal force should be applied at a height equal to the maximum wave height $h_{\max }$ measured without the building. In practical 
terms, this depth would be obtained by a design engineer from a detailed numerical model of the inundation or from the application of the Energy Grade Line method, as prescribed by the ASCE7-6 (2016) standard.

(4) While the reduction in terms of horizontal forces and associated moments remained limited for buildings subject to minor overtopping $\left(d_{0}=0.63 \mathrm{~m}\right)$, for major overtopping $\left(d_{0}=0.82 \mathrm{~m}\right)$, the differences were more significant. This showed a dependence of forces and moments on the water depth overtopping the building. However, this parameter is difficult to derive from the basic hydrodynamic properties of the wave such as water depth and flow velocity. An iterative process is thus needed.

\section{Funding}

The study was supported by the Swiss National Science Foundation [grant number 200021_149112/1 and 200021_149112/2].

\section{Notation}

\begin{tabular}{|c|c|c|}
\hline$B$ & $=$ & building width $B=0.3(\mathrm{~m})$ \\
\hline$C_{R}$ & $=$ & generic resistance coefficient $(-)$ \\
\hline$C_{R, S}$ & $=$ & $\begin{array}{l}\text { resistance coefficient in case of overtopping } \\
(-)\end{array}$ \\
\hline$d_{0}$ & $=$ & $\begin{array}{l}\text { equivalent impoundment depth for a dam- } \\
\text { break wave }(\mathrm{m})\end{array}$ \\
\hline$F_{x}, F_{y}, F_{z}$, & $=$ & force in $x, y$ and $z$ directions $(\mathrm{N})$ \\
\hline$F_{x, D}$ & $=$ & computed horizontal force $(\mathrm{N})$ \\
\hline$g$ & $=$ & gravity constant, $g=9.81\left(\mathrm{~m} \mathrm{~s}^{-2}\right)$ \\
\hline$H$ & $=$ & wave height with the building (m) \\
\hline$h$ & $=$ & wave height without the building (m) \\
\hline$h_{0}$ & $=$ & initial still water depth (m) \\
\hline$H_{B}$ & $=$ & building height $(\mathrm{m})$ \\
\hline$H_{e q}$ & $=$ & equivalent overtopping depth [eq. (12)] (m) \\
\hline$h_{M}$ & $=$ & $\begin{array}{l}\text { relative wave height at } F=F_{x, \max } \text { [eq. (6)] } \\
\text { (m) }\end{array}$ \\
\hline I & $=$ & impulse, $I=F \cdot \Delta t(\mathrm{~N} \mathrm{~s})$ \\
\hline$I^{*}$ & $=$ & ratio between $I_{\text {peak }}$ and $I_{\text {tot }}[$ eq. (9)] ( -$)$ \\
\hline$I_{\text {peak }}$ & $=$ & $\begin{array}{l}\text { impulse in the interval } T=0 \text { to } T=\tau_{\max } \text { [eq. } \\
(8)](\mathrm{N} \mathrm{s})\end{array}$ \\
\hline$I_{\text {tot }}$ & $=$ & total impulse [eq.(7)] $(\mathrm{N} \mathrm{s})$ \\
\hline$L_{z}$ & $=$ & cantilever arm defined in eq. (10) (m) \\
\hline$M$ & $=$ & $\begin{array}{l}\text { wave momentum flux per unit width [eq.(3)] } \\
\left(\mathrm{m}^{3} \mathrm{~s}^{-2}\right)\end{array}$ \\
\hline$M^{*}$ & $=$ & $\begin{array}{l}\text { modified momentum flux per unit width } \\
\text { [eq.(4)] }\left(\mathrm{m}^{3} \mathrm{~s}^{-2}\right)\end{array}$ \\
\hline$M_{x}, M_{y}, M_{z}$ & $=$ & moment around $x, y$ and $z$ axis $(\mathrm{N} \mathrm{m})$ \\
\hline$M_{y, D}$ & $=$ & computed moment around $y$-axis $(\mathrm{Nm})$ \\
\hline $\mathrm{R}_{\mathrm{e}}$ & $=$ & Reynold number $(-)$ \\
\hline$S$ & $=$ & overtopping coefficient defined in eq. (13) $(-)$ \\
\hline$T$ & & $\begin{array}{l}\text { shifted time such that the impact occurs at } \\
T=0 \text { (s) }\end{array}$ \\
\hline
\end{tabular}

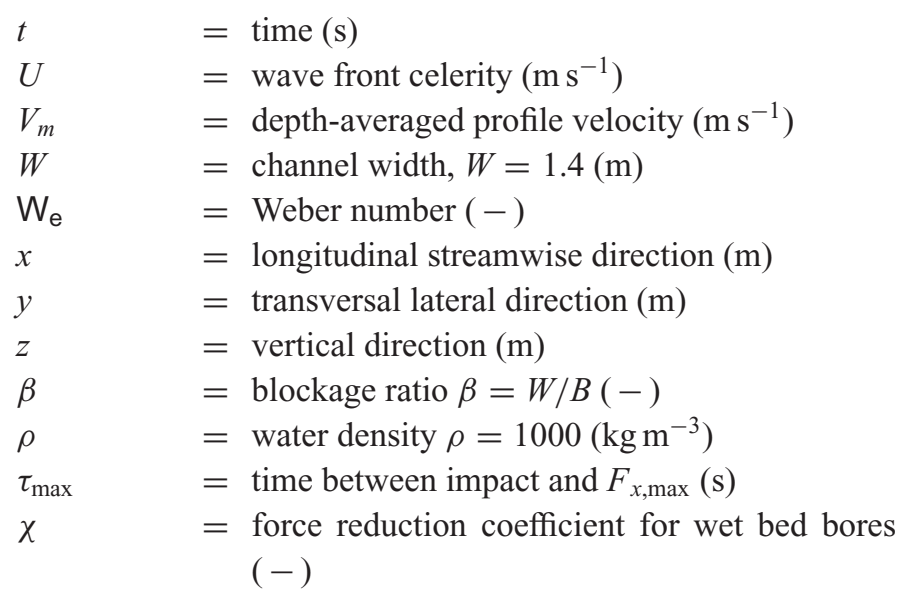

\section{ORCID}

Davide Wüthrich (D) http://orcid.org/0000-0003-1974-3560

Ioan Nistor (D) http://orcid.org/0000-0001-8436-4781

Anton J. Schleiss (D) http://orcid.org/0000-0003-1559-5740

\section{References}

Al-Faesly, T., Palermo, D., Nistor, I., \& Cornett, A. (2012). Experimental modeling of extreme hydrodynamic forces on structural models. International Journal of Protective Structures, 3(4), 477-505.

Arnason, H., Petroff, C., \& Yeh, H. (2009). Tsunami bore impingement onto a vertical column. Journal of Disaster Research, 4(6), 391-403.

Asakura, R., Iwase, K., Ikeya, T., Takao, M., Kaneto, K., Fujii, N., \& Omori, M. (2000). An experimental study on wave force acting on on-shore structures due to overflowing tsunamis. Proceedings of Coastal Engineering, 47, 911-915. (in Japanese).

ASCE7-6 (Structural Engineering Institute). (2016). Minimum design loads for buildings and other structures. Reston, VA: ASCE/SEI 7-16.

Bullock, G., Crawford, A., Hewson, P., Walkden, M., \& Bird, P. (2001). The influence of air and scale on wave impact pressures. Coastal Engineering, 42(4), 291-312.

Bullock, G., Obhrai, C., Peregrine, D., \& Bredmose, H. (2007). Violent breaking wave impacts. part 1: Results from largescale regular wave tests on vertical and sloping walls. Coastal Engineering, 54(8), 602-617.

CCH. (2000). City and County of Honolulu building code (CCH), Department of Planning and Permitting of Honolulu Hawaii, Chapter 16, Article 11.

Chanson, H. (2004). The hydraulics of open channel flow: An introduction. Oxford, UK: Elsevier Ltd. 581 pages.

Chanson, H. (2006). Tsunami surges on dry coastal plains: Application of dam break wave equations. Coastal Engineering Journal, 48(4), 355-370. 
Chanson, H., Aoki, S., \& Maruyama, M. (2002). An experimental study of tsunami run-up on dry and wet horizontal coastlines. International Journal of the Tsunami Society, Science of Tsunami Hazards, 20(5), 278-293.

Chen, X., Hofland, B., Altomare, C., Suzuki, T., \& Uijttewaal, W. (2015). Forces on a vertical wall on a dike crest due to overtopping flow. Coastal Engineering, 95, 94-104.

Chen, X., Hofland, B., \& Uijttewaal, W. (2016). Maximum overtopping forces on a dike-mounted wall with a shallow foreshore. Coastal Engineering, 116, 89-102.

Chock, G., Robertson, I., Kriebel, D., Francis, M., \& Nistor, I. (2012). Tohoku Japan tsunami of March 11, 2011 - Performance of structures. American Society of Civil Engineers (ASCE), 348 pages.

Cross, R. (1967). Tsunami surge forces. Journal of the Waterways and Harbors Division, 93(4), 201-231.

Esteban, M., Glasbergen, T., Takabatake, T., Hofland, B., Nishizaki, S., Nishida, Y., ... Shibayama, T. (2017). Overtopping of Coastal structures by tsunami waves. Geosciences, $7,121$.

Foster, A. S. J., Rossetto, T., \& Allsop, W. (2017). An experimentally validated approach for evaluating tsunami inundation forces on rectangular buildings. Coastal Engineering, 128, 44-57.

Fritz, H., Phillips, D., Okayasu, A., Shimozono, T., Liu, H., Mohammed, F., ... Takahashi, T. (2012). The 2011 japan tsunami current velocity measurements from survivor videos at kesennuma bay using lidar. Geophysical Research Letters, 39, $1-6$.

Fuchs, H. (2013). Solitary impulse wave run-up and overland flow (ETH PhD Thesis). (No. 21174) and VAW Mitteilung 221, (Ed. R. Boes). Zürich, Switzerland, 178 pages.

Fujima, K., Achmad, F., Shigihara, Y., \& Mizutani, N. (2009). Estimation of Tsunami Force Acting on Rectangular Structures. Journal of Disaster Research, 4(6), 404- 409.

Gupta, V. P., \& Goyal, S. C. (1975). Hydrodynamic forces on bridge piers. Journal of the Institution of Engineers (India), Civil Engineering Division, 56, 12-16.

Iizuka, H., \& Matsutomi, H. (2000). Damage due to flood flow of tsunami. Proceedings of the Coastal Engineering of JSCE, 47, 381-385.

Jaffe, B., Goto, K., Sugawara, D., Richmond, B., Fujino, S., \& Nishimura, Y. (2012). Flow speed estimated by inverse modeling of sandy tsunami deposits: results from the 11 March 2011 tsunami on the coastal plain near the Sendai Airport, Honshu, Japan. Sedimentary Geology, 282, 90-109.

Lauber, G., \& Hager, W. H. (1998). Experiments to dam-break wave: Horizontal channel. Journal of Hydraulic Research, 36(3), 291-307.

Lukkunaprasit, P., Thanasisathit, N., \& Yeh, H. (2009). Experimental verification of FEMA p646 tsunami loading. Journal of Disaster Research, 4(6), 410-418.

Madsen, P., Fuhrman, D., \& Schäffer, H. (2008). On the solitary wave paradigm for tsunamis. Journal of
Geophysical Research: Oceans, (1978-2012), 113(C12), 1-22.

Meile, T., Boillat, J. L., \& Schleiss, A. J. (2011). Water-surface oscillations in channels with axi-symmetric cavities. Journal of Hydraulic Research, 49(1), 73-81.

Nakano, Y. (2008). Design load evaluation for tsunami shelters based on damage observations after Indian Ocean tsunami disaster due to the 2004 Sumatra earthquake. The 14th World Conference on Earthquake Engineering, Beijing, China, 1217 October.

Nistor, I., Palermo, D., Nouri, Y., Murty, T., \& Saatcioglu, M. (2009). Tsunami-induced forces on structures. Handbook of coastal and ocean engineering (pp. 261-286). Singapore: World Scientific.

Nouri, Y., Nistor, I., Palermo, D., \& Cornett, A. (2010). Experimental investigation of tsunami impact on free standing structures. Coastal Engineering Journal, 52(1), 43-70.

Okada, T., Sugano, T., Ishikawa, T., Ohgi, T., Takai, S., \& Hamabe, C. (2005). Structural design methods of buildings for tsunami resistance (SMBTR). Japan: The Building Center of Japan.

Qi, Z., Eames, I., \& Johnson, E. (2014). Force acting on a square cylinder fixed in a free-surface channel flow. Journal of Fluid Mechanics, 756, 716-727.

Rahman, S., Akib, S., Khan, M., \& Shirazi, S. (2014). Experimental study on tsunami risk reduction on coastal building fronted by sea wall. The Scientific World Journal, 2014, 7 pages.

Ramsden, J. D. (1996). Forces on a vertical wall due to long waves, bores, and dry-bed surges. Journal of Waterway, Port, Coastal, and Ocean Engineering, 122(3), 134-141.

Ritter, A. (1892). Die Fortpflanzung der Wasserwellen. Zeitschrift Verein Deutscher Ingenieure, 36(33), 947-954.

Rossetto, T., Allsop, W., Charvet, I., \& Robinson, D. (2011). Physical modelling of tsunami using a new pneumatic wave generator. Coastal Engineering, 58(6), 517-527.

Schüttrumpf, H., \& Oumeraci, H. (2005). Scale and model effects in crest level design. Proceedings of the 2nd International Coastal Symposium in Iceland, Höfn, Iceland, 5-8 June.

Shafiei, S., Melville, B. W., \& Shamseldin, A. Y. (2016). Experimental investigation of tsunami bore impact force and pressure on a square prism. Coastal Engineering, 110, 1-16.

Stoker, J. J. (1957). Water waves: The mathematical theory with applications. Intersciences, 567 pages.

Wüthrich, D. (2018). Extreme Hydrodynamic impact onto buildings (EPFL PhD Thesis). (N. 8116). Lausanne, Switzerland, 264 pages.

Wüthrich, D., Pfister, M., Nistor, I., \& Schleiss, A. J. (2018a). Experimental study of tsunami-like waves generated with a vertical release technique on dry and wet beds. Journal of Waterway, Port, Coastal, and Ocean Engineering, 144(4), 04018006. 
Wüthrich, D., Pfister, M., Nistor, I., \& Schleiss, A. J. (2018b). Experimental study on the hydrodynamic impact of tsunami-like waves against impervious freestanding buildings. Coastal Engineering Journal, 60(2), 180-199.

Wüthrich, D., Pfister, M., Nistor, I., \& Schleiss, A. J. (2018c). Experimental study on forces exerted on buildings with openings due to extreme hydrodynamic events. Coastal Engineering, 140, 72-86.
Wüthrich, D., Pfister, M., \& Schleiss, A. J. (2016). Example of wave impact on a residential house. Proceedings of the 4th IAHR Europe Congress, Liege, Belgium, 27-29 July 2016.

Yeh, H. (2007). Design tsunami forces for onshore structures. Journal of Disaster Research, 2(6), 531-536.

Yeh, H., Liu, P., \& Synolakis, C. (1996). Long-wave runup models. Singapore: World Scientific Publishing Co., 403 pages. 